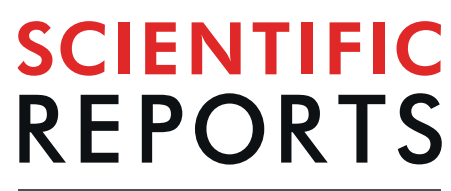

natureresearch

\title{
Ultrasound imaging links soleus muscle neuromechanics and energetics during human walking with elastic ankle exoskeletons
}

\begin{abstract}
R. W. Nuckols ${ }^{1,2,3^{*}}$, T. J. M. Dick ${ }^{1,4}$, O. N. Beck ${ }^{5}$ \&. S. Sawicki ${ }^{1,5^{*}}$
Unpowered exoskeletons with springs in parallel to human plantar flexor muscle-tendons can reduce the metabolic cost of walking. We used ultrasound imaging to look 'under the skin' and measure how exoskeleton stiffness alters soleus muscle contractile dynamics and shapes the user's metabolic rate during walking. Eleven participants ( $4 \mathrm{~F}, 7 \mathrm{M}$; age: $27.7 \pm 3.3$ years) walked on a treadmill at $1.25 \mathrm{~m} \mathrm{~s}^{-1}$ and $0 \%$ grade with elastic ankle exoskeletons (rotational stiffness: $0-250 \mathrm{Nm} \mathrm{rad}^{-1}$ ) in one training and two testing days. Metabolic savings were maximized (4.2\%) at a stiffness of $50 \mathrm{Nm} \mathrm{rad}^{-1}$. As exoskeleton stiffness increased, the soleus muscle operated at longer lengths and improved economy (force/activation) during early stance, but this benefit was offset by faster shortening velocity and poorer economy in late stance. Changes in soleus activation rate correlated with changes in users' metabolic rate $\left(p=0.038, R^{2}=0.44\right)$, highlighting a crucial link between muscle neuromechanics and exoskeleton performance; perhaps informing future 'muscle-in-the loop' exoskeleton controllers designed to steer contractile dynamics toward more economical force production.
\end{abstract}

The plantar flexors serve an essential role in human walking by providing more than $50 \%$ of the leg's total positive mechanical energy ${ }^{1}$ and up to $60 \%$ of the mechanical power output for redirecting the body's center of mass during push-off ${ }^{2}$. The importance of the ankle plantar flexors in legged locomotion is linked to their morphology. Muscle-tendons (MTs) with short pennate muscle fibers and long compliant in-series tendons are well suited for economical locomotion because the elastic tendons store and return mechanical energy over each step ${ }^{3-5}$. During steady-state walking, the interaction of the plantar flexors and Achilles tendon is tuned. Throughout early stance, $0 \%$ (heel strike) to $40 \%$ stride, plantar flexor muscle fascicles generate force isometrically while the Achilles tendon stretches and stores mechanical energy ${ }^{6}$. In late stance, $40 \%$ to $60 \%$ (toe-off) stride, the plantar flexors shorten and the tendon rapidly recoils, providing a burst of positive mechanical power ${ }^{1,4,7}$. This coordinated MT interaction permits the plantar flexor muscle fascicles to operate over a narrow region of their force-length (F-L) curve and remain at slow shortening velocities which are favorable contractile conditions for economical force production $^{7-12}$. Any disruption to this 'catapult' like mechanism may decrease the ankle's efficient mechanical power production and worsen walking efficiency.

Exoskeletons are a class of wearable devices that often act in parallel with human MTs to restore or augment human movement. An increasing number of studies ${ }^{13}$ are establishing that both tethered ${ }^{14-18}$ and portable ${ }^{19-21}$ lower-limb exoskeletons can deliver mechanical power to the body to reduce metabolic demand during walking in young healthy individuals ${ }^{14-22}$, individuals post-stroke ${ }^{23}$, and older adults ${ }^{24,25}$. Recently, our group has demonstrated that exoskeletons need not deliver net external mechanical power to the body to reduce the metabolic rate of walking ${ }^{26}$. We showed that elastic exoskeletons that place a tension spring in parallel with the human plantar flexor-Achilles tendon complex can reduce the net metabolic rate of walking by an average of $7.2 \%{ }^{26}$ versus not using a device. The relationship between the user's net metabolic rate and the rotational stiffness of the

\footnotetext{
${ }^{1}$ Joint Department of Biomedical Engineering, UNC Chapel Hill and NC State University, Raleigh, NC, 27607, USA. 2John A. Paulson School of Engineering and Applied Sciences, Harvard University, Cambridge, MA, 02138, USA. ${ }^{3}$ Wyss Institute for Biologically Inspired Engineering, Harvard University, Cambridge, MA, 02138, USA. ${ }^{4}$ School of Biomedical Sciences, University of Queensland, St Lucia, Queensland, Australia. ${ }^{5}$ George W. Woodruff School of Mechanical Engineering and School of Biological Sciences, Georgia Institute of Technology, Atlanta, GA, 30332, USA. *email: rnuckols@seas.harvard.edu; gregory.sawicki@me.gatech.edu
} 


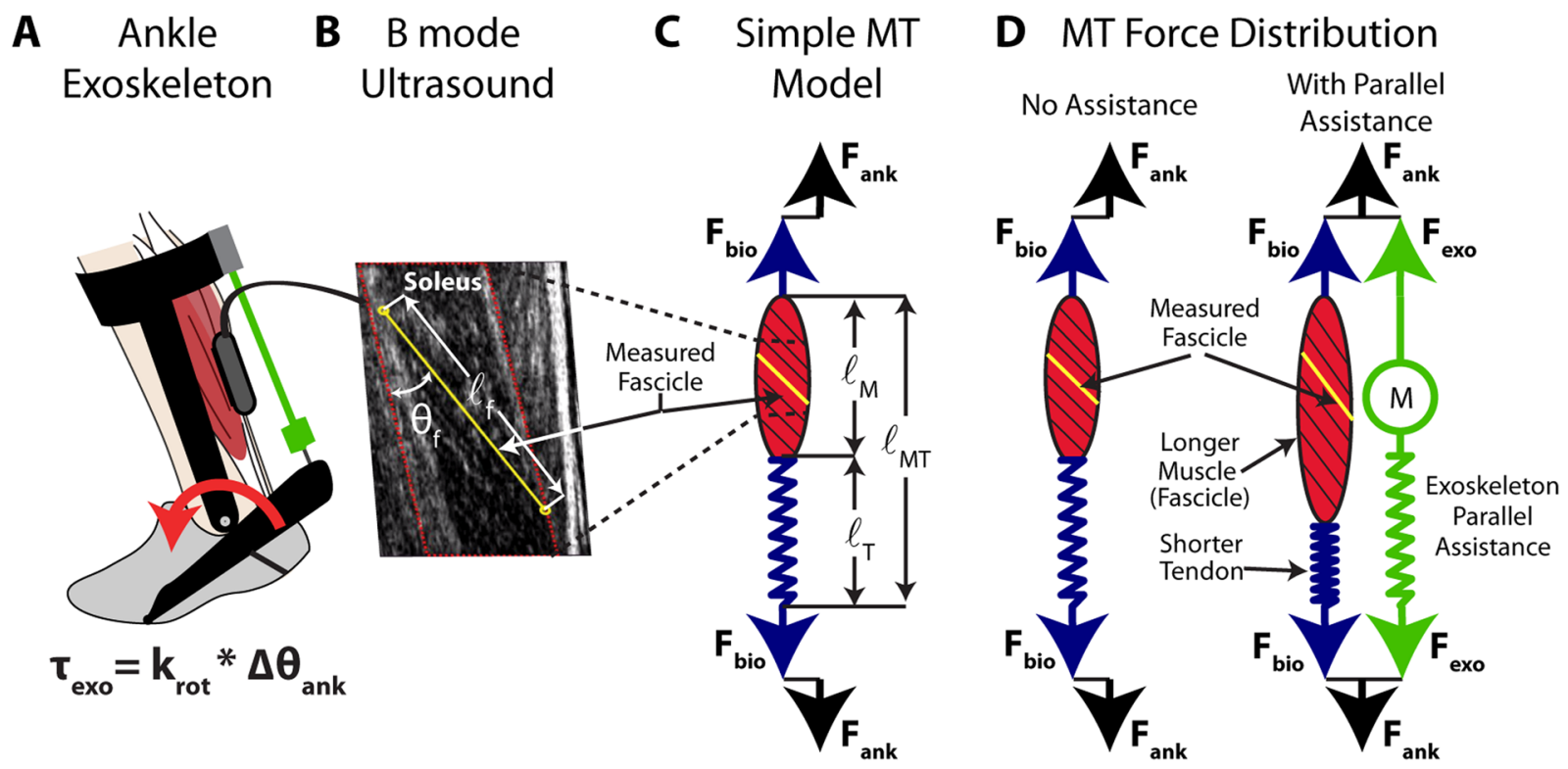

Figure 1. Conceptual model of an ankle exoskeleton providing parallel assistance to a plantar flexor muscletendon. (A) Schematic of an ankle exoskeleton that applies a plantar flexor torque about the human ankle joint. In this study, the torque behaved like a rotational spring $\left(\tau_{\mathrm{exo}}=\mathrm{k}_{\mathrm{rot}} * \Delta \theta_{\mathrm{ank}}\right)$ but conceptually could be any torque resulting from an exoskeleton force acting in parallel with a biological muscle-tendon. (B) We recorded B-mode ultrasound data from a probe attached to the shank over the soleus. We digitized images using automated tracking software to determine time-varying soleus fascicle lengths $\left(\ell_{\mathrm{f}}\right)$ and pennation angles $\left(\theta_{\mathrm{f}}\right)$. (C) In our simplified conceptual model, the muscle-tendon (MT) is comprised of a muscle (M) and tendon (T)

(lengths $=\ell_{\mathrm{mt}}, \ell_{\mathrm{m}}$, and $\ell_{\mathrm{t}}$ respectively) acting in series to produce a biological force $\left(\mathrm{F}_{\mathrm{bio}}\right)$ which generates a torque about the ankle through a moment arm (not shown for simplicity). (D) Without exoskeleton assistance $\left(\mathrm{F}_{\text {exo }}=0\right)$, the entirety of the ankle force $\left(\mathrm{F}_{\mathrm{ank}}\right)$ is directed through the biological structure $\left(\mathrm{F}_{\text {bio }}=\mathrm{F}_{\text {ank }}\right)$. With exoskeleton assistance in parallel, a portion of the total ankle force is shunted to the exoskeleton resulting in a decrease in the biological force requirements $\left(\mathrm{F}_{\mathrm{bio}}=\mathrm{F}_{\mathrm{ank}}-\mathrm{F}_{\mathrm{exo}}\right)$. As a result of decreased biological force and because the tendon is a passive element, we expect the tendon strain to decrease by $\Delta \ell_{\mathrm{T}}=\Delta \mathrm{F}_{\text {bio }} *$ (tendon stiffness). Finally, if length changes of the MT do not change much, we expect the muscle fascicles to be longer when exoskeleton parallel assistance is applied. In this study, we tested this hypothesis by using ultrasound to directly measure soleus fascicle length during walking with elastic ankle exoskeletons over a broad range of stiffnesses.

exoskeleton is bowl-shaped, with a 'sweet-spot' that maximizes metabolic benefit where exoskeleton stiffness is not too compliant, is not too stiff, but just right.

Experimental evidence indicates that when exoskeletons are too stiff, a metabolic penalty arises from a series of compensatory changes in mechanics at the knee and hip as well as increased activation of the plantar flexor's antagonist muscle, the tibialis anterior ${ }^{26}$. In addition to compensatory mechanisms at more proximal joints, local changes in ankle plantar flexor muscle dynamics may also help explain why increasing exoskeleton stiffness does not continue to improve metabolic rate during walking. Although increased exoskeleton stiffness reduces force requirements on the plantar flexors, the tuned MT interaction may become disrupted and result in poorer muscle economy (force/activation) and increased metabolic rate. This disruption of MT interaction which elicits less economical muscle dynamics is predicted by models and simulations of hopping ${ }^{27,28}$, walking ${ }^{29-31}$ and running ${ }^{32}$ and has been demonstrated experimentally in both human hopping ${ }^{33}$ and in isolated animal muscle experiments that use a biorobotic interface to simulate exoskeleton interaction dynamics ${ }^{34}$. During human hopping, an exoskeleton providing stiffness in parallel to the ankle plantar flexors reduced muscle force and net metabolic rate, but increased soleus muscle positive work due to greater fascicle excursions ${ }^{33}$. In a follow-up modelling study using the same hopping dataset, ankle exoskeleton torque reduced soleus fascicle operating lengths and increased fascicle velocities ${ }^{27}$, which both acted to limit the estimated metabolic savings from using the device. Musculoskeletal simulations of walking with a unilateral elastic exoskeleton have demonstrated that applying ankle exoskeleton torque to the ankle joint reduces muscle force requirements, which leads to decreased tendon stretch and increased fascicle strain ${ }^{17}$. This trend is also supported by a recent study that used ultrasound imaging to track the junction between the medial gastrocnemius and Achilles tendon during walking with a dynamic orthosis ${ }^{35}$. Together, these studies demonstrate that exoskeletons may disrupt the normal plantar flexor MT dynamics by limiting the ability of series-elastic tissues to keep plantar flexor muscles operating with contractile dynamics favorable for economical force production ${ }^{30}$.

Rather than relying on model-based estimates, we sought to use ultrasound imaging techniques to directly examine whether increasing ankle exoskeleton stiffness disrupts plantar flexor muscle-tendon dynamics during walking (Fig. 1). To date, no study has linked in vivo measurements of muscle dynamics to a user's net metabolic 


\begin{tabular}{|c|c|c|c|c|c|c|}
\hline & & \multicolumn{5}{|c|}{ Exoskeleton Stiffness (Nm rad ${ }^{-1}$ ) } \\
\hline & & 0 & 50 & 100 & 150 & 250 \\
\hline \multirow{3}{*}{ Muscle Fascicle Force Rate $\left(\mathrm{N} \mathrm{kg}^{-1} \mathrm{~s}^{-1}\right)$} & $\begin{array}{l}\text { Stance } \\
p<0.0001\end{array}$ & $12.9 \pm 0.6$ & $\begin{array}{l}11.7 \pm 0.6 \\
p=0.0099\end{array}$ & $\begin{array}{l}10.9 \pm 0.6 \\
p<0.0001\end{array}$ & $\begin{array}{l}10.6 \pm 0.7 \\
p<0.0001\end{array}$ & $\begin{array}{l}10.6 \pm 0.8 \\
p<0.0001\end{array}$ \\
\hline & Early Stance & $12.6 \pm 1.2$ & $12.2 \pm 1.2$ & $11.4 \pm 1.1$ & $11.6 \pm 1.2$ & $12.4 \pm 1.6$ \\
\hline & \begin{tabular}{|l|} 
Late Stance \\
$p<0.0001$ \\
\end{tabular} & $65.5 \pm 2$ & $\begin{array}{l}56.6 \pm 1.7 \\
p<0.0001 \\
\end{array}$ & $\begin{array}{l}52.8 \pm 1.9 \\
p<0.0001 \\
\end{array}$ & $\begin{array}{l}49.2 \pm 2.3 \\
p<0.0001 \\
\end{array}$ & $\begin{array}{l}46.1 \pm 1.6 \\
p<0.0001 \\
\end{array}$ \\
\hline \multirow{3}{*}{ Soleus Activation Rate $\left(\mathrm{s}^{-1}\right)$} & Stance & $0.39 \pm 0.03$ & $0.36 \pm 0.02$ & $0.35 \pm 0.02$ & $0.35 \pm 0.03$ & $0.36 \pm 0.04$ \\
\hline & $\begin{array}{l}\text { Early Stance } \\
p=0.0023\end{array}$ & $0.44 \pm 0.04$ & $0.38 \pm 0.04$ & $\begin{array}{l}0.34 \pm 0.04 \\
p=0.0046\end{array}$ & $\begin{array}{l}0.35 \pm 0.04 \\
p=0.0073\end{array}$ & $\begin{array}{l}0.35 \pm 0.05 \\
p=0.0103\end{array}$ \\
\hline & Late Stance & $1.34 \pm 0.06$ & $1.31 \pm 0.06$ & $1.29 \pm 0.05$ & $1.28 \pm 0.08$ & $1.27 \pm 0.09$ \\
\hline Fascicle Length (mm) & $\begin{array}{l}@ \text { Peak Force } \\
p<0.0001\end{array}$ & $38.3 \pm 1.7$ & $39.4 \pm 1.5$ & $40.3 \pm 1.8$ & $\begin{array}{l}42.3 \pm 1.8 \\
p<0.0001\end{array}$ & $\begin{array}{l}42.7 \pm 1.8 \\
p<0.0001\end{array}$ \\
\hline Fascicle Velocity $\left(\mathrm{mm} \mathrm{s}^{-1}\right)$ & $\begin{array}{l}@ \text { Peak Force } \\
p=0.0318\end{array}$ & $0.5 \pm 2.6$ & $0.9 \pm 3$ & $2.6 \pm 2.7$ & $3.6 \pm 2.6$ & $4.2 \pm 2.3$ \\
\hline \multirow{3}{*}{ Force Per Activation $\left(\mathrm{N} \mathrm{kg}^{-1}\right)$} & Stance & $41.1 \pm 4.7$ & $40.1 \pm 4.7$ & $41.4 \pm 5.0$ & $40.2 \pm 5.2$ & $40.8 \pm 4.7$ \\
\hline & $\begin{array}{l}\text { Early Stance } \\
p<0.0001\end{array}$ & $30.5 \pm 4.6$ & $34.7 \pm 5.7$ & $38.6 \pm 7.6$ & $38.3 \pm 7.8$ & $38.9 \pm 5.5$ \\
\hline & $\begin{array}{l}\text { Late Stance } \\
p<0.0001\end{array}$ & $61.1 \pm 6.3$ & $49.2 \pm 4.3$ & $50.4 \pm 5.5$ & $\begin{array}{l}46.4 \pm 4.5 \\
p=0.0351\end{array}$ & $\begin{array}{l}46.2 \pm 4.7 \\
p=0.0325\end{array}$ \\
\hline
\end{tabular}

Table 1. Muscle level changes due to exoskeleton assistance. Values are mean \pm SEM across $N=10$ participants. [main effect: stiffness]. Post-Hoc test (THSD) on determine significant difference from $0 \mathrm{Nm} \mathrm{rad}^{-1}$. Early stance is defined as $0-40 \%$ of the gait cycle and late stance is $40-60 \%$. (Note: The rate represents an average moment/ activation per unit time and is not a measure of how rapidly the moment/activation is generated).

rate during walking with exoskeletons. We used B-mode ultrasound imaging to measure soleus muscle fascicle contractile dynamics in vivo during exoskeleton assisted walking across a range of ankle exoskeleton rotational stiffnesses $\left(\mathrm{k}_{\mathrm{exo}}=0,50,100,150,250 \mathrm{Nm} \mathrm{rad}^{-1}\right)$. We predicted that stiffer ankle exoskeletons would disrupt the normally tuned catapult behavior of the ankle plantar flexors. Specifically, we hypothesized that increasing exoskeleton stiffness would (1) reduce soleus muscle fascicle force, (2) reduce soleus activation, (3) increase soleus fascicle length and (4) shortening velocity, and (5) alter soleus force per unit activation (i.e., muscle economy or force production capacity). Taken together, we posit that ankle exoskeleton assistance elicits a trade-off between reduced soleus force on one hand and a shift to contractile conditions that are less economical for force production on the other. We suggest that this balance explains the metabolic 'sweet-spot' at intermediate elastic ankle exoskeletons stiffness during walking.

\section{Results}

To highlight the effect of exoskeleton stiffness on biomechanics and walking economy, the results focus on the effect of two exoskeleton stiffnesses with respect to the $0 \mathrm{Nm} \mathrm{rad}^{-1}$ (no assistance) condition. The $50 \mathrm{Nm} \mathrm{rad}^{-1}$ condition details what occurs with a stiffness that is low but results in the metabolic minimum. The $250 \mathrm{Nm} \mathrm{rad}^{-1}$ condition details what occurs at a perceptually very stiff condition which also resulted the metabolic maximum. Response for other conditions are reported in figures and Table 1.

Metabolic cost. We found a significant relationship between net metabolic rate and the square of exoskeleton stiffness (mixed-model ANOVA; $\mathrm{k}_{\text {exo }}^{2} p=0.022 ;$ Metabolic Rate $\left(\mathrm{W} \mathrm{kg}^{-1}\right)=$ $3.1-9.73 \times 10^{-4} \times \mathrm{k}_{\text {exo }}+7.05 \times 10^{-6} \times \mathrm{k}_{\text {exo }}^{2}$ ). Elastic ankle exoskeletons providing $50 \mathrm{Nm} \mathrm{rad}^{-1}$ of rotational stiffness decreased net metabolic rate during walking at $1.25 \mathrm{~m} \mathrm{~s}^{-1}$ by $4.2 \%$ with respect to the $0 \mathrm{Nm} \mathrm{rad}^{-1}$ condition (CI: $<0.4 \%, 7.8 \%>$; two tailed paired t-test; $p=0.032$ ) (Fig. 2A). Metabolic demand at $250 \mathrm{Nm} \mathrm{rad}^{-1}$ was $4.7 \%$ higher than $0 \mathrm{Nm} \mathrm{rad}^{-1}$.

Spatio-temporal parameters. Increasing ankle exoskeleton stiffness reduced stride time (ANOVA; $p=0.0203$ ) and stance time (ANOVA; $p=0.0012$ ) but did not significantly affect swing time (ANOVA; $p=0.6454$ ) or stance to swing ratio (ANOVA; $p=0.1559$ ). Stride time and stance time decreased by $\sim 0.04 \mathrm{sec}-$ onds $(4 \%)$ at the stiffest condition compared to the $0 \mathrm{Nm} \mathrm{rad}^{-1}$ condition. Stance to swing ratio was $\sim 0.63$ across all exoskeleton stiffness conditions.

Ankle joint dynamics. Peak ankle dorsiflexion angle decreased as exoskeleton stiffness increased (ANOVA; $p<0.0001$ ) (Fig. 2B). Relative to $0 \mathrm{Nm} \mathrm{rad}^{-1}$, peak ankle dorsiflexion decreased from $17.9 \pm 1.2 \mathrm{deg}$. (mean \pm SEM) to $15.0 \pm 1.3 \mathrm{deg}$. for $50 \mathrm{Nm} \mathrm{rad}^{-1}$ and to $8.1 \pm 1.4 \mathrm{deg}$. for $250 \mathrm{Nm} \mathrm{rad}^{-1}$. Increasing exoskeleton stiffness increased exoskeleton torque (ANOVA; $p<0.0001$ ) and decreased biological ankle moment (ANOVA; $p<0.0001$ ) (Fig. 2C). At $50 \mathrm{Nm} \mathrm{rad}^{-1}$, the exoskeleton provided a peak torque of $0.20 \pm 0.01 \mathrm{Nm}$ $\mathrm{kg}^{-1}$ and decreased biological ankle moment by $12 \%$ from $1.59 \pm 0.04 \mathrm{Nm} \mathrm{kg}^{-1}$ to $1.41 \pm 0.03 \mathrm{Nm} \mathrm{kg}^{-1}$. At 250 $\mathrm{Nm} \mathrm{rad}{ }^{-1}$, exoskeleton torque reached a peak of $0.47 \pm 0.03 \mathrm{Nm} \mathrm{kg}^{-1}$ and reduced biological ankle moment by $28 \%$ to $1.14 \pm 0.04 \mathrm{Nm} \mathrm{kg}^{-1}$. Increasing exoskeleton stiffness increased exoskeleton mechanical power (ANOVA; $p<0.0001$ ) and reduced biological ankle mechanical power (ANOVA; $p<0.0001$ ) (Fig. 2D). At $50 \mathrm{Nm} \mathrm{rad}^{-1}$, exoskeleton positive mechanical power was $0.036 \pm 0.003 \mathrm{~W} \mathrm{~kg}^{-1}$ and average biological positive mechanical 
A
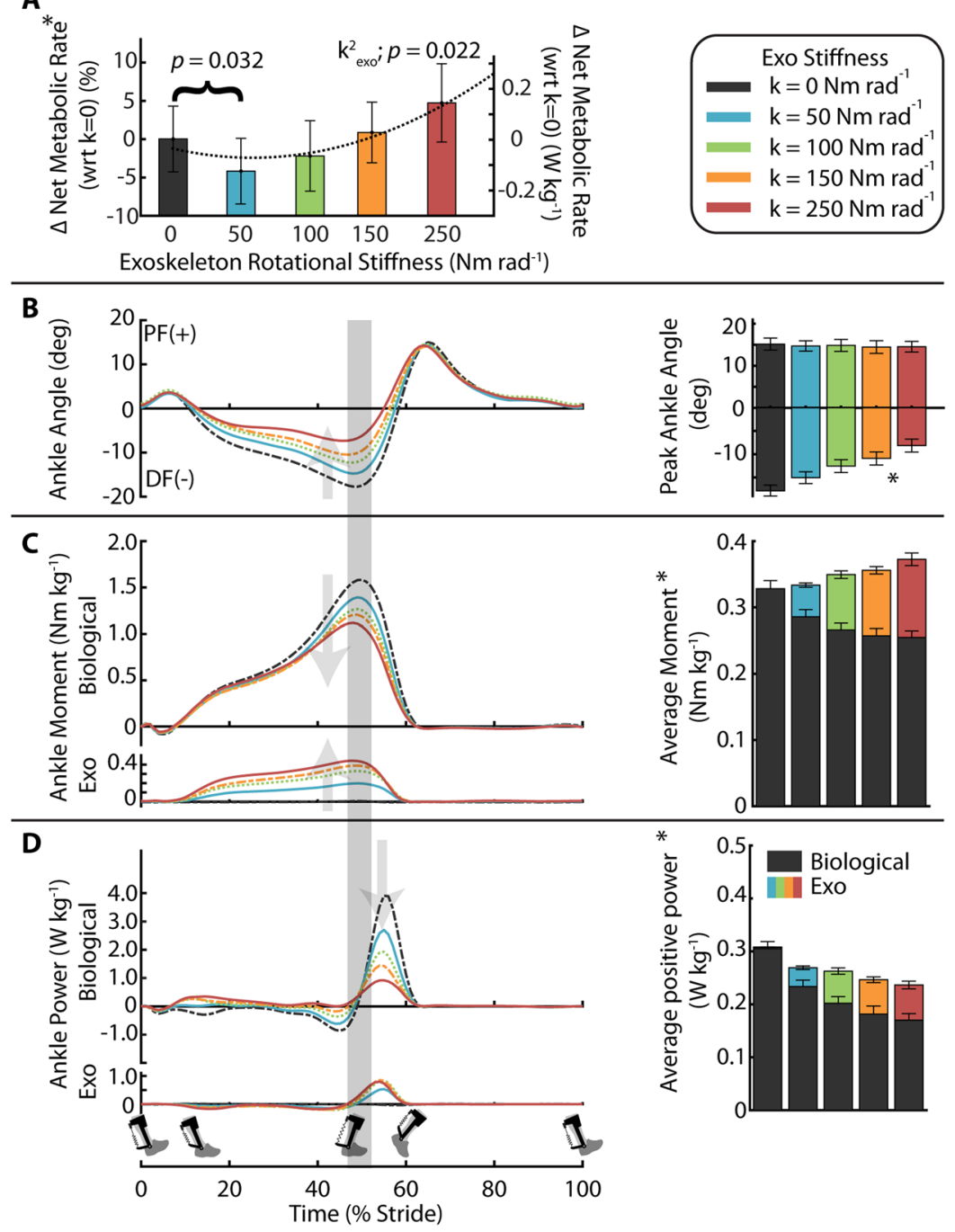

Figure 2. Effect of elastic ankle exoskeleton on metabolic demand and ankle joint dynamics. (A) Percent difference in metabolic rate for each stiffness relative to the zero-stiffness condition. Metabolic rate was minimized at $50 \mathrm{Nm} \mathrm{rad}^{-1}$ (ANOVA; $\mathrm{k}_{\text {exo }}^{2} p=0.022$ ). (B) Time series of ankle joint plantar flexion (PF) and dorsiflexion (DF) angle averaged over participants. Peak ankle dorsiflexion angle was reduced with increased ankle exoskeleton stiffness. (C) Mass normalized biological moment (top) and exoskeleton torque (bottom) for each stiffness. Stacked bar charts represent the average biological (black-lower) and exoskeleton (colorsupper) contribution to total ankle moment for the stride. Increasing exoskeleton stiffness resulted in increased exoskeleton torque and decreased biological moment. (D) Time series of 6DOF biological (top) and exoskeleton (bottom) power for each stiffness. Stacked charts represent average biological (black, lower) and exoskeleton (colors, upper) power over the stride. Exoskeleton power remained fairly constant at high stiffnesses while biological power decreased with increased stiffness. Region of peak force highlighted in time series data. All bars graphs show mean \pm SEM across $\mathrm{N}=11$ participants. [Main effect: stiffness, ${ }^{*} p<0.0001$ (BIO, EXO, and ANK)].

power decreased from $0.305 \pm 0.013 \mathrm{~W} \mathrm{~kg}^{-1}$ to $0.233 \pm 0.012 \mathrm{~W} \mathrm{~kg}^{-1}$. At $250 \mathrm{Nm} \mathrm{rad}^{-1}$, exoskeleton positive mechanical power was $0.066 \pm 0.007 \mathrm{~W} \mathrm{~kg}^{-1}$ and average biological positive mechanical power decreased to $0.170 \pm 0.012 \mathrm{~W} \mathrm{~kg}^{-1}$.

Soleus muscle dynamics. Soleus muscle force decreased with increasing exoskeleton stiffness (Fig. 3A, Table 1). Peak force was greatest at the $0 \mathrm{Nm} \mathrm{rad}^{-1}$ condition, $21.88 \pm 0.72 \mathrm{~N} \mathrm{~kg}^{-1}$, and minimized at the $250 \mathrm{Nm}$ $\operatorname{rad}^{-1}$ condition, $15.18 \pm 0.67 \mathrm{~N} \mathrm{~kg}^{-1}$. Reduced soleus force was reflected by decreased average force rate over the stance phase $(0-60 \%$ stride) (ANOVA; $p<0.0001)$ (Fig. 3A) (Note: The rate represents an average moment per unit time and is not a measure of how rapidly the moment is generated). Compared to $0 \mathrm{Nm} \mathrm{rad}^{-1}$ condition, average soleus force rate of stance reduced by $12 \%$ and $18 \%$ for 50 and $250 \mathrm{Nm} \mathrm{rad}^{-1}$ respectively (Fig. 3Ai). There was no reduction in force rate of early stance ( $0-40 \%$ stride) (ANOVA; $p=0.38$ ) (Fig. 3Aii). The change in average force rate of stance was primarily from the decrease in the average force rate of late stance (40-60\% stride) (ANOVA; $p<0.0001$ ) which, compared to $0 \mathrm{Nm} \mathrm{rad}^{-1}$, was reduced by $14 \%$ and $29 \%$ for 50 and $250 \mathrm{Nm} \mathrm{rad}^{-1}$ respectively (Fig. 3Aiii). 
A
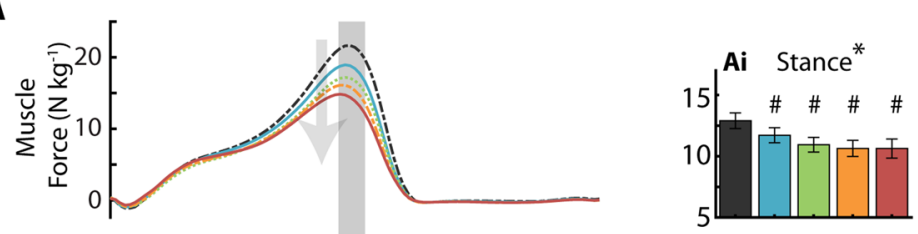

Muscle Force Rate $\left(\mathrm{N} \mathrm{kg}^{-1} \mathrm{~s}^{-1}\right)$

B
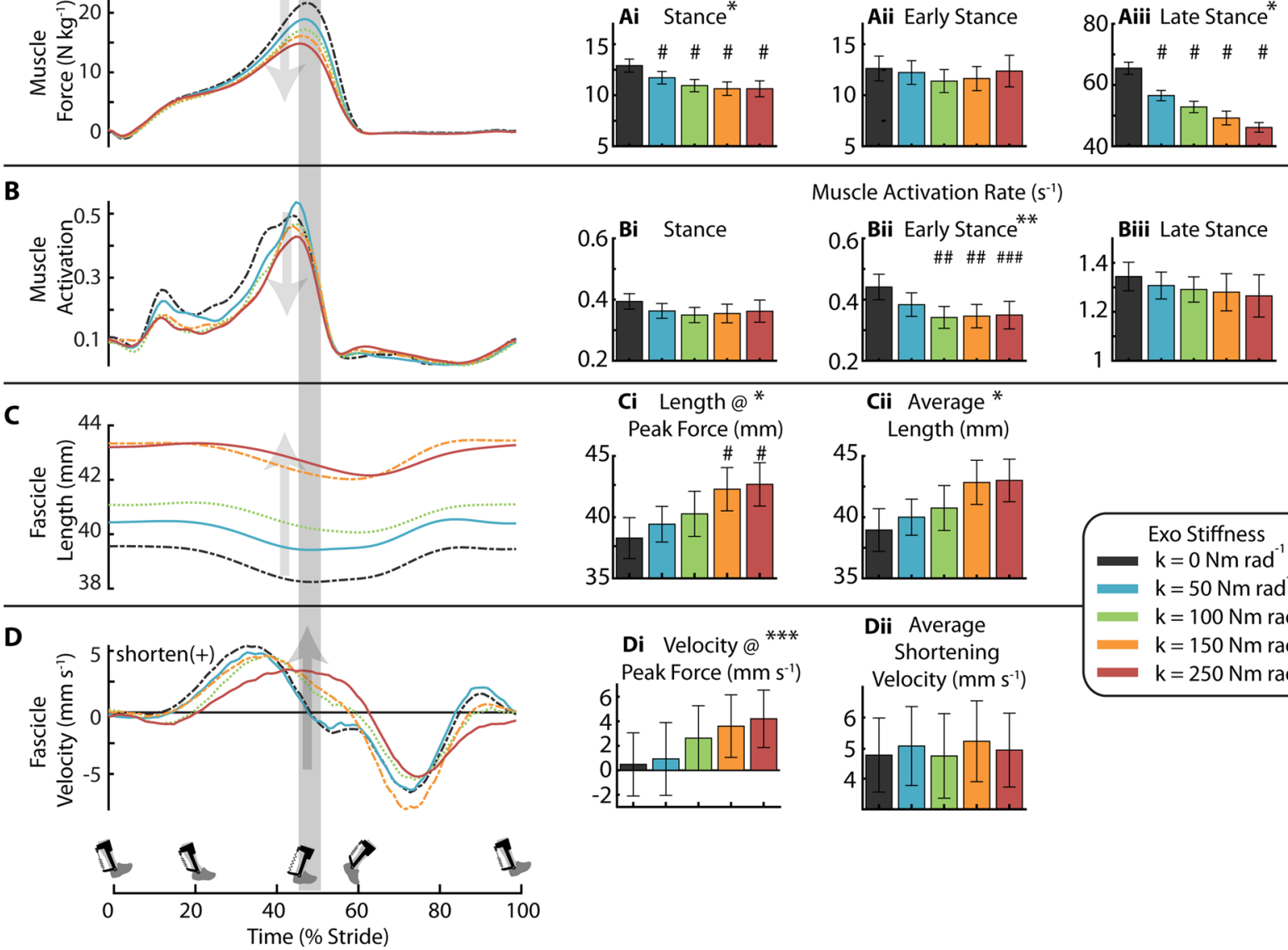

Muscle Activation Rate $\left(\mathrm{s}^{-1}\right)$
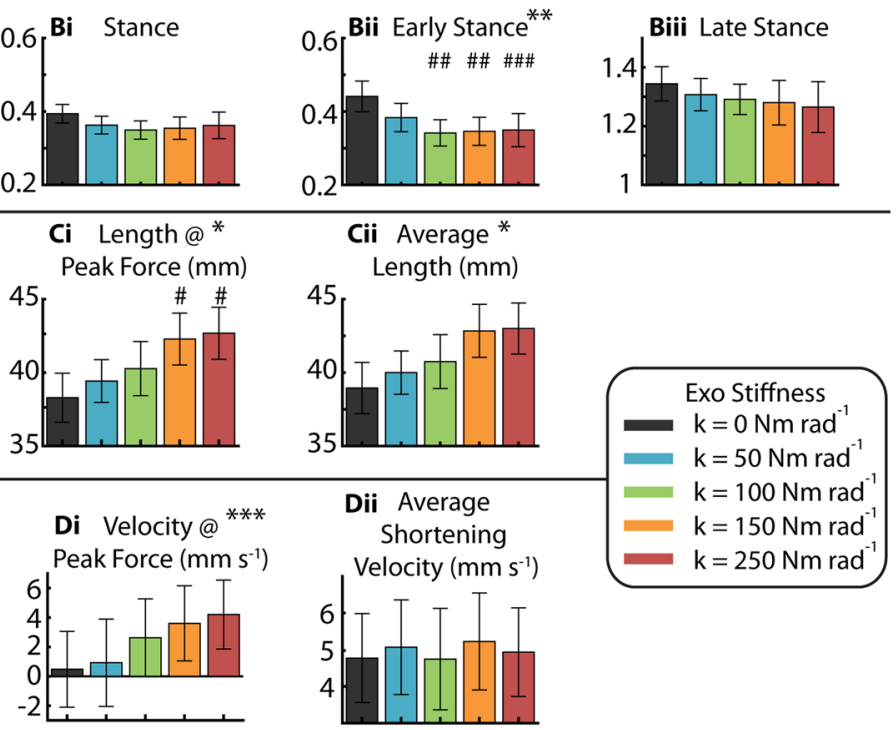

Figure 3. Effect of elastic ankle exoskeleton stiffness on soleus muscle-tendon dynamics. (A) Soleus force for each exoskeleton stiffness averaged over participants. Region of peak force highlighted in time series data. Bar charts represent the soleus muscle force rate for (Ai) stance, (Aii) early stance ( $0-40 \%$ stride), and (Aiii) late stance (40-60\% stride). Increasing exoskeleton stiffness resulted in decreased soleus force rate for stance and late stance. (B) Time series of soleus muscle activation where amplitude is normalized to the peak activation across all stiffnesses for each participant. Bar charts are soleus muscle activation rate in (Bi) stance, (Bii) early stance, and (Biii) late stance. Soleus activation rate decreased with increasing exoskeleton assistance in early stance. (C) Time series of soleus fascicle length and bar charts representing $(\mathrm{Ci})$ length at peak fascicle force and (Cii) average length during stance. Fascicle length increased with increasing exoskeleton stiffness. (D) Time series of soleus fascicle velocity measured and bar charts representing (Di) velocity at peak fascicle force and (Dii) average shortening velocity during stance. Fascicle shortening velocity at peak increases with stiffness. All bars graphs show mean \pm SEM across $\mathrm{N}=10$ participants. [Main effect: stiffness, ${ }^{*} p<0.0001, * * p=0.0023$, $* * * p=0.0318$; THSD: $\left.{ }^{\#} p<0.0001,{ }^{\# \#} p<0.01,{ }^{\# \# \#} p<0.05\right]$.

Soleus average activation rate, as measured by surface electromyography (EMG), decreased with increasing exoskeleton stiffness during early stance (ANOVA; $p=0.0023$ ) (Fig. 3B and Table 1 ). The reduction in activation rate of early stance was $14 \%$ and $21 \%$ for the 50 and $250 \mathrm{Nm} \mathrm{rad}^{-1}$ condition compared to $0 \mathrm{Nm} \mathrm{rad}^{-1}$ (Fig. 3Bii). There was no change in activation rate of late stance (ANOVA $p=0.8765$ ) (Fig. 3Biii).

The peak length of the soleus MT decreased with increasing exoskeleton stiffness (ANOVA; $p<0.0001$ ). Compared to $0 \mathrm{Nm} \mathrm{rad}{ }^{-1}$, MT peak length decreased from $308 \pm 6.6 \mathrm{~mm}$ to $306 \pm 6.9 \mathrm{~mm}$ in the $50 \mathrm{Nm} \mathrm{rad}^{-1}$ condition and to $301 \pm 6.9 \mathrm{~mm}$ in the $250 \mathrm{Nm} \mathrm{rad}^{-1}$ condition (Supp. Fig. 1C).

Ankle exoskeletons altered both soleus fascicle length and velocity dynamics. Stiffer exoskeletons increased fascicle average length during all of stance (ANOVA; $p<0.0001)$ and during the time of peak force (ANOVA; $p<0.0001)$ (Figs. 3C, 4A and Table 1). Compared to fascicle length at $0 \mathrm{Nm} \mathrm{rad}^{-1}(38.3 \pm 1.6 \mathrm{~mm})$, fascicle length at the time of peak force increased by $2.9 \%$ and $11.4 \%$ in the 50 and $250 \mathrm{Nm} \mathrm{rad}^{-1}$ conditions respectively (Figs. 3Ci, 4A); likely shifting the respective fascicles toward their optimal length $\left(l_{0}\right)$ on the F-L curve (Fig. 4C).

Soleus fascicles shortened faster during stance with increasing exoskeleton stiffness, and this was reflected by increased fascicle velocity at the time of peak force (ANOVA; $p=0.0318$ ) (Figs. 3D, $4 \mathrm{D}$ and Table 1). Compared to the fascicle velocity at the time of peak force for $0 \mathrm{Nm} \mathrm{rad}^{-1}\left(0.47 \pm 2.6 \mathrm{~mm} \mathrm{~s}^{-1}\right)$, fascicle shortening velocity increased by $0.4 \pm 1.2 \mathrm{~mm} \mathrm{~s}^{-1}$ and $3.7 \pm 1.6 \mathrm{~mm} \mathrm{~s}^{-1}$ in the 50 and $250 \mathrm{Nm} \mathrm{rad}^{-1}$ conditions, respectively (Figs. 3Di, 4D), shifting the soleus fascicles towards their maximum shortening velocity (Fig. 4F). No condition was significantly different from $0 \mathrm{Nm} \mathrm{rad}^{-1}$ (THSD: $p>0.05$ ). 


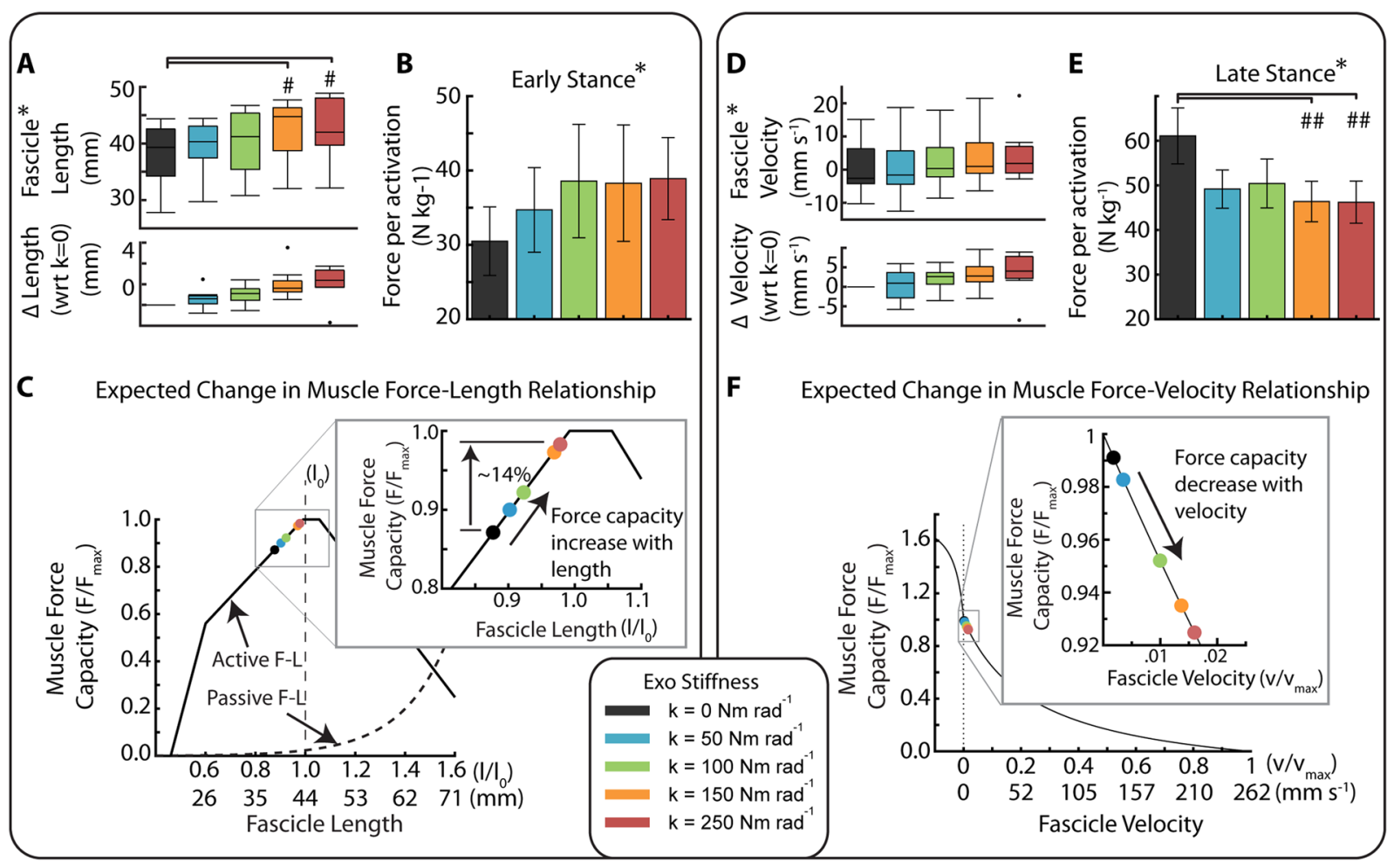

Figure 4. Trade-off in force-length-velocity behavior links users' soleus fascicle dynamics and economy of force production. (A) (Top) Soleus fascicle length at peak fascicle force for each stiffness. (Bottom) Difference in soleus fascicle length at peak force relative to the zero stiffness conditions. The two high stiffness conditions (orange and red) were significantly longer than $0 \mathrm{Nm} \mathrm{rad}^{-1}$ (ANOVA $* p<0.0001$; THSD ${ }^{\#} p<0.0001$ ). (B) Average muscle force per activation (i.e., muscle economy) during early stance (0-40\%) of the gait cycle. Muscle economy increased $(* p<0.0448)$ with increased exoskeleton stiffness as might be expected from improved operating point on the F-L curve during early stance. (C) Fascicle operating length at peak force relative to estimated muscle force-length (F-L) curve with optimal length $l_{0}=43.6 \mathrm{~mm}$ and inset of a narrowed scale. Data indicate a rightward shift of the F-L curve with increased exoskeleton stiffness and increased force production capacity. (D) (Top) Soleus fascicle velocity at peak fascicle force for each stiffness $\left({ }^{*} p=0.032\right)$. (Bottom) Difference in soleus fascicle velocity at peak force relative to the zero stiffness conditions. (E) Average muscle force per activation during late stance (40-60\%) of the gait cycle. Muscle economy decreased with increased exoskeleton stiffness as might be expected from a shift in operating point on the F-V curve during late stance. The two high stiffness conditions (orange and red) were significantly different than $0 \mathrm{Nm} \mathrm{rad}^{-1}$ (ANOVA ${ }^{*} p=0.0258$; THSD ${ }^{\# \#} p=0.0351$ and 0.0325 ). (F) Fascicle operating point at peak force on estimated muscle force-velocity (F-V) curve assuming $\mathrm{v}_{\max }$ of $262 \mathrm{~mm} \mathrm{~s}^{-1}$. Shift in muscle velocity to the right with increased stiffness shown in inset due to narrow range of shortening velocities near $\mathrm{v}=0 \mathrm{~mm} \mathrm{~s}^{-1}$. All bars graphs show mean \pm SEM across $\mathrm{N}=10$ participants.

Ankle exoskeletons had no effect on soleus fascicle pennation angle during the stance phase. Neither the pennation angle at the time of peak force $(26.6 \pm 0.8 \mathrm{deg}$; ANOVA; $p=0.1007)$ nor the average pennation angle over stance ( $25.8 \pm 0.8 \mathrm{deg}$; ANOVA; $p=0.2301)$ changed across exoskeleton stiffness conditions (Supp. Fig. 1D).

Exoskeletons affected the economy of soleus force production in a phase dependent manner during stance; likely improving it during early stance and worsening it during late stance. Soleus muscle economy increased in early stance (ANOVA; $p=0.0448$ ) (Fig. $4 \mathrm{~B}$, Table 1 ), increasing by $14 \%$ and $27 \%$ for 50 and $250 \mathrm{Nm} \mathrm{rad}^{-1} \mathrm{respec}^{-}$ tively compared to $0 \mathrm{Nm} \mathrm{rad}^{-1}$. Soleus muscle economy decreased in late stance (ANOVA; $p=0.0258$ ) (Fig. 4E), decreasing by $20 \%$ and $24 \%$ at 50 and $250 \mathrm{Nm} \mathrm{rad}^{-1}$ compared to $0 \mathrm{Nm} \mathrm{rad}^{-1}$.

Association between soleus neuromechanics and whole-body net metabolic rate. We found a positive correlation (LLSR: $p<0.038, \mathrm{R}^{2}=0.44$ ) (Table 2, Fig. 5) between the change in average soleus activation rate of stance (i.e., $\Delta=$ with respect to the zero exoskeleton stiffness condition) and $\Delta$ in whole-body net metabolic rate. In addition, we found a significant positive correlation (LLSR: $p<0.016, \mathrm{R}^{2}=0.42$ ) (Table 2) between $\Delta$ soleus force rate in early stance phase and $\Delta$ whole-body net metabolic rate. Finally, we found a negative correlation between $\Delta$ soleus force (LLSR: $p=0.0018, \mathrm{R}^{2}=0.53$ ) and $\Delta$ soleus force rate (LLSR: $p=0.0005, \mathrm{R}^{2}=0.59$ ) (Table 2) during late stance and $\Delta$ whole-body net metabolic rate. 


\begin{tabular}{|c|c|c|c|}
\hline \multirow{2}{*}{$\begin{array}{l}\text { Gait Cycle Phase } \\
\text { (\% Stride) }\end{array}$} & Total Stance (TS) & Early Stance (ES) & Late Stance (LS) \\
\hline & $0-60 \%$ & $0-40 \%$ & $40-60 \%$ \\
\hline $\begin{array}{l}\Delta \text { Muscle Positive Power [Fig. 2D] } \\
\left(\mathrm{J} \mathrm{kg}^{-1} \mathrm{~s}^{-1}\right)\end{array}$ & $\mathrm{p}=0.97$ & - & - \\
\hline $\begin{array}{l}\Delta \text { Muscle Force } \\
\left(\mathrm{N} \mathrm{kg}^{-1} \mathrm{~s}^{-1}\right)\end{array}$ & $\mathrm{p}=0.45$ & $\mathrm{p}=0.09$ & $\begin{array}{l}\mathrm{y}=-0.27-0.07 x \\
\mathrm{p}=0.0005, \mathrm{R}^{2}=0.59\end{array}$ \\
\hline $\begin{array}{l}\Delta \text { Muscle Force Rate [Fig. 3A] } \\
\left(\mathrm{N} \mathrm{kg}^{-1} \mathrm{~s}^{-1}\right)\end{array}$ & $\mathrm{p}=0.37$ & $\begin{array}{l}y=0.01+0.03 x \\
p=0.016, R^{2}=0.42\end{array}$ & $\begin{array}{l}y=-0.26-0.02 x \\
p=0.0018, R^{2}=0.53\end{array}$ \\
\hline $\begin{array}{l}\Delta \text { Muscle Activation } \\
\text { (unitless) }\end{array}$ & $\mathrm{p}=0.41$ & $\mathrm{p}=0.41$ & $\mathrm{p}=0.64$ \\
\hline $\begin{array}{l}\Delta \text { Muscle Activation Rate [Fig. 3B] } \\
\left(\mathrm{s}^{-1}\right)\end{array}$ & $\begin{array}{l}\mathrm{y}=0.03+1.27 \mathrm{x} \\
\mathrm{p}=0.038, \mathrm{R}^{2}=0.44\end{array}$ & $\mathrm{p}=0.08$ & $\mathrm{p}=0.57$ \\
\hline $\begin{array}{l}\Delta \text { Force/ } \Delta \text { Muscle Activation [Fig. 4B,E] } \\
\left(\mathrm{N} \mathrm{kg}^{-1}\right)\end{array}$ & $\mathrm{p}=0.64$ & $\mathrm{p}=0.91$ & $\mathrm{p}=0.63$ \\
\hline
\end{tabular}

Table 2. The relationships between the change in net metabolic rate $\left(\mathrm{W} \mathrm{kg}^{-1}\right)(\mathrm{y})$ and changes in soleus muscle neuromechanics $(\mathrm{x})$ during walking with exoskeletons over a range of stiffness values, $\mathrm{k}_{\mathrm{exo}}$. For each metric, $\Delta$ represents the difference from the $\mathrm{k}_{\mathrm{exo}}=0$ condition (i.e., the effect of increasing exoskeleton stiffness) with positive values indicating an increase. We used a within-participant linear regression analysis to determine whether relationships were significant $(p<0.05)$, and for those that were, we report the line of best fit to the data and the $\mathrm{R}^{2}$ value of the fit. Bold underline indicates a significant relationship between the change in a given neuromechanical variable, $x$ and the change in whole-body net metabolic rate, $y$.

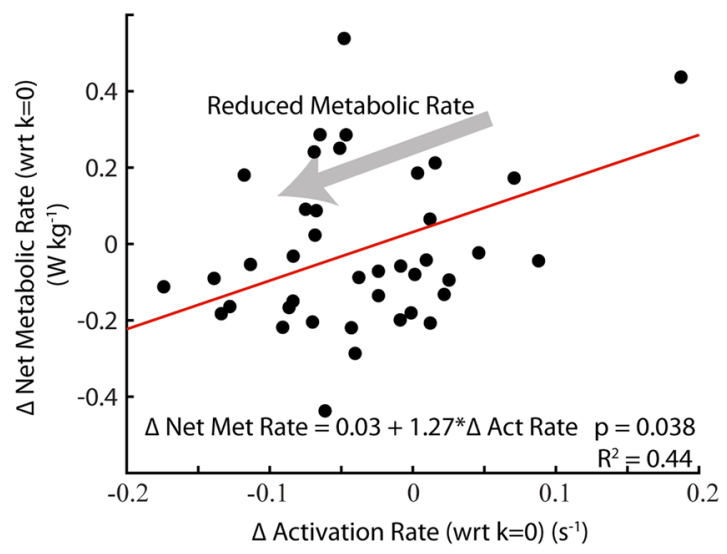

Figure 5. Relationship between rate of muscle activation and metabolic rate. Change net metabolic rate $\left(\mathrm{W} \mathrm{kg}^{-1}\right)$ plotted against change in soleus activation rate (unitless $\left.\mathrm{s}^{-1}\right)$ with respect to no assistance $(\mathrm{k}=0 \mathrm{Nm}$ $\left.\operatorname{rad}^{-1}\right)$. Changes in soleus activation rate were significantly correlated with changes in users' net metabolic rate $\left(p=0.038 ; \mathrm{R}^{2}=0.44\right)$.

\section{Discussion}

This study's overarching hypothesis was that despite reducing plantar flexor force requirements during walking, elastic ankle exoskeletons would detune the catapult-like interaction within the plantar flexor MTs, affect the economy of plantar flexor force production, and yield a muscle-level metabolic change. As hypothesized, applying rotational stiffness to the ankle with elastic exoskeletons altered plantar flexor muscle dynamics. At a walking speed of $1.25 \mathrm{~m} \mathrm{~s}^{-1}$, increasing exoskeleton rotational stiffness resulted in decreased soleus force (Fig. 3A) and increased soleus fascicle length and shortening velocity at the time of peak force (Figs. 3C,D and 4A,D). These results provide the first empirical evidence to support predictions from previous modelling and simulation studies that used an in silico approach to examine changes in plantar flexor muscle-dynamics during walking with spring-loaded ${ }^{30}$ and actively powered ${ }^{29}$ ankle exoskeletons. Our approach provides an in vivo experimental framework that can be used to explore how exoskeletons may be used to steer (i.e., direct) muscle fascicle dynamics to reduce users' net metabolic rate ${ }^{36}$.

A muscle's capacity to produce force is, in part, governed by the intrinsic force-length (F-L) and force-velocity (F-V) relationships ${ }^{9-11,37-39}$. In human walking, soleus fascicles normally operate on the ascending limb of the F-L curve $^{8}$. While we did not characterize our participants' soleus fascicle optimal lengths $\left(l_{o}\right)$, the average fascicle length during walking with zero exoskeleton stiffness $\left(0 \mathrm{Nm} \mathrm{rad}^{-1}\right)$ was $\sim 39 \mathrm{~mm}$, which is up to $11 \%$ shorter than soleus optimal lengths reported in previous studies ${ }^{40}$. A study that mapped participants' soleus length changes during walking at self-selected speed $\left(\right.$ mean $\left.=1.14 \mathrm{~ms}^{-1}\right)$ onto their empirically determined F-L curves found that humans operate at a nearly constant fascicle length of $\sim 0.9 l_{0}$ over early stance ${ }^{8}$. Assuming those in our study also operated at $\sim 0.9 l_{0}$, we estimate the soleus optimal length of $43.6 \mathrm{~mm}(39.2 \mathrm{~mm} / 0.9)$ for our participants. 
When operating on the ascending limb of the F-L curve, a shift to longer fascicle lengths should increase muscle force capacity, especially when considering the contribution of passive muscle forces at lengths greater than the optimal length ${ }^{41}$. Using equations for theoretical active and passive F-L relationships taken from Golapudi and $\operatorname{Lin}^{42}$ and our estimate of group average $l_{0}$ of $43.6 \mathrm{~mm}$, we calculated that the $\sim 4 \mathrm{~mm}$ increase in soleus fascicle length at $250 \mathrm{Nm} \mathrm{rad}^{-1}$ (Figs. 3C, 4A) would shift the muscle's operating length onto the plateau of the F-L curve and therefore could increase soleus force capacity by as much as $12 \%$ compared to $0 \mathrm{Nm} \mathrm{rad}^{-1}$ (Fig. $4 \mathrm{C}$ ). Thus, walking with increased ankle exoskeleton stiffness likely resulted in a length-dependent increase in soleus force capacity during early stance.

With respect to soleus fascicle shortening velocity, muscle force capacity is most sensitive to changes in velocity near the isometric region of the F-V curve ${ }^{10}$, and a shift to faster shortening velocities decreases force capacity $^{10}$. In this study, for $0 \mathrm{Nm} \mathrm{rad}{ }^{-1}$ the average fascicle velocity during stance $\left(\sim 5 \mathrm{~mm} \mathrm{~s}^{-1}\right)$ and velocity at the time of peak force $\left(\sim 0.5 \mathrm{~mm} \mathrm{~s}^{-1}\right)$ were considerably less than the reported maximum shortening velocity $\left(v_{\max }\right)$ of the soleus $\left(\sim 6^{*} l_{o}, 262 \mathrm{~mm} \mathrm{~s}^{-1}\right)^{30}$ (Fig. 3D). These slow shortening velocities coincide with previous research suggesting that the soleus operates near isometrically during early stance in walking ${ }^{7,8,12}$. Using an equation from Alexander $1997^{43}$ and a $v_{\max }$ of $262 \mathrm{~mm} \mathrm{~s}^{-1}$, we calculated that the relatively small $\sim 4.0 \mathrm{~mm} \mathrm{~s}^{-1}$ increase in soleus fascicle shortening velocity at the time of peak force (Figs. 3D, 4D) for the $250 \mathrm{Nm} \mathrm{rad}^{-1}$ condition would reduce force capacity by $6.7 \%$ compared to $0 \mathrm{Nm} \mathrm{rad}^{-1}$ (Fig. 4F). Thus, walking with increased ankle exoskeleton stiffness likely resulted in a velocity-dependent decrease in soleus force capacity during late stance. The impact of increasing exoskeleton stiffness on muscle length and velocity dynamics presents an interesting trade-off with respect to the metabolic energy cost of soleus force production.

Inspired by a plethora of locomotion research linking changes in metabolic rate $\left(\dot{E}_{m e t}\right)$ to changes in rate of active muscle volume $\left(\frac{V_{a c t}}{T_{a c t}}\right)^{44-50}\left(\dot{E}_{\text {met }}=\alpha \cdot \frac{V_{a c t}}{T_{a c t}}\right)$, we examined the factors that influence the rate of active soleus muscle volume during walking with elastic ankle exoskeletons (see Supplementary Analysis (S1) for detailed analysis). We found evidence that elastic ankle exoskeletons influence whole-body net metabolic rate $\dot{E}_{\text {met }}$ primarily through their impact on soleus muscle activation rate (Fig. 3B) during the stance phase of walking (Table 2, Fig. 5). Our mechanistic framework (S1, Eqs. S1-S7) revealed that elastic exoskeletons modified soleus activation rate not just by modulating force demand (S1, Eqs. S3, S4 and Fig. 3A), but also by modifying soleus length change dynamics (Figs. 3C,D, 4A,D) - shifting the muscle's operating point on its F-L and F-V curves (Fig. 4C,F) subsequently impacting its force capacity (S1, Eqs. S5-S7; Fig. 4B,E). These findings represent the first empirical evidence that show changes in local plantar flexor muscle dynamics well-explain the 'bowl-shaped' relationship between elastic ankle exoskeleton stiffness and user's net metabolic rate ${ }^{26,51}$.

The rate of soleus active muscle volume $\left(\frac{V_{\text {act }}}{T_{\text {act }}}\right)$ captures the changes in local muscle dynamics (e.g., force, length, velocity, and ultimately activation) due to elastic ankle exoskeleton torque and can explain a significant portion $(\sim 44 \%$, (Table 2$)$ ) of the change in whole-body net metabolic rate with increasing exoskeleton stiffness. Although substantial, the rate of soleus active muscle volume explains less than $50 \%$ of the change in net metabolic rate across exoskeleton stiffness. Even though the soleus is presumably one of the body's most metabolically active muscles during locomotion due to its relatively large force output ${ }^{47-49,52,53}$, and ankle exoskeletons likely alter muscle dynamics at the ankle more than knee or hip muscle dynamics ${ }^{26,27,54}$, there are other muscles ${ }^{55}$ and factors that contribute to whole-body metabolic energy expenditure ${ }^{55}$.

From a theoretical and purely mechanical perspective, users should be able to maximize the benefits of the exoskeleton by replacing the biological moment with an equivalent contribution from the exoskeleton. To do this, users would 'shut off' their plantar flexor muscles to minimize the biological moment/power requirements and take full advantage of exoskeleton moment/power. However, we found that the total (biological plus exoskeleton) net ankle moment increased with increasing exoskeleton stiffness (Fig. 2C), indicating that users did not equally reduce the forces in their plantar flexors (Fig. 3A) by the amount that would have been required to maintain a consistent total ankle moment. In addition to our results, many other studies ${ }^{51,56-59}$ also indicate that as exoskeleton assistance increases, humans do not 'shut off' their muscles and rely on exoskeleton assistance alone; instead a cascade of local and global neuromechanical compensations arise. For example, we observed decreased ankle dorsiflexion (Fig. 2B) and a plateau in exoskeleton torque across the highest stiffness values (Fig. 2C), along with increased tibialis anterior activity ${ }^{51}$ and knee flexion moment at terminal stance ${ }^{51}$. These compensations may functionally reduce injury potential, as studies have shown that the biological system may be resistant to increased strain on the muscles as a mechanism to prevent eccentric muscle damage ${ }^{60-63}$. We observed a $\sim 10 \%$ increased soleus fascicle strain from the 0 to the $250 \mathrm{Nm} \mathrm{rad}^{-1}$ exoskeleton condition (Fig. 4A,C), well below the strain levels that have been reported to be damaging $\left(>1.25 l_{o}\right)^{63}$. However, if users had not reduced their dorsiflexion in late stance as much as they did (Fig. 2B) ( equivalent to $7 \mathrm{~mm}$ MT excursion (see Supp. Fig. 3C)) while maintaining the same torque profile, we predict that peak fascicle lengths would have approached the $25 \%>l_{0}$ level. Furthermore, the observed compensations in ankle kinematics (e.g., increased plantar flexion angle) were similar to the kinematic compensations observed during a study of human hopping with elastic ankle exoskeletons ${ }^{33}$ where injury prevention may have also been a factor.

Another potential explanation for users not taking advantage of maximum exoskeleton stiffness could be based in an inability to reduce their soleus muscle activation in proportion to the level of assistance provided. Research has shown that joints (and limbs) tend to maintain constant stiffness during a given locomotor condition ${ }^{37}$ which may be accomplished through a combination of stretch sensors (e.g., muscle spindle organs) and force sensors (e.g., golgi tendon organs) that are responsible for maintaining a nearly constant ratio between the change in muscle force and length ${ }^{64-66}$. Because exoskeleton torque decreased soleus force and increased fascicle length, the apparent stiffness of the MT was likely markedly reduced. Therefore, a mismatch in sensory feedback from the force (golgi tendon organ) and length (spindle organ) related mechanoreceptors could be a possible explanation for why we do not observe reductions in activation proportional to the level of applied exoskeleton assistance. Limb-joint 
stiffness control may be further regulated through higher neural centers, but much of walking is automatic and unconsciously controlled though spinal-level central pattern generators, reflexes, cerebellar regulation, and the brainstem ${ }^{67}$. For this reason, exoskeleton users may not be able to easily turn off their plantar flexors, which would be required to further minimize whole-body net metabolic rate across a broad range of stiffnesses. Further work in both humans and non-human animals $s^{34,68}$ is necessary to understand the interaction between altered muscle fascicle dynamics and feedforward/feedback neural control mechanisms during walking with exoskeletal devices.

We acknowledge certain potential limitations. The sessions were split among a training day and two testing days and there is the potential for day to day variability. Our goal was to balance the conditions that could be studied with the fatigue of the individual. Because individuals were trained and healthy young adults with no muscular or neurological issues, we thought the tradeoff acceptable. In our analysis and interpretation of muscle fascicle dynamics, while we were able to measure the dynamics of the muscle using ultrasound, certain measurements were simplified or calculated based on common assumptions. We did not measure optimal fascicle length directly but estimated that the optimal fascicle length is $\sim 0.9 * l_{0}^{8}$. The Achilles Tendon moment arm is geometrically derived ${ }^{69}$ rather than capturing the full complexity ${ }^{70,71}$. Due to our inability to directly measure soleus force and power, we used joint torque and assumed a distribution among redundant plantar flexor muscles based on relative muscle cross-sectional areas ${ }^{72}$ and no antagonist co-contraction.

In terms of application, our results highlight the importance of the morphology of the MTs that a device interacts with, unpowered or powered. Exoskeleton induced changes to the F-L operating point may provide an even greater benefit in populations where MT dynamics are already disrupted. Given the non-linear curvature of muscle's F-L relationship, a given shift in muscle length could induce a larger improvement in economy when starting from even shorter lengths. For example, Achilles tendon compliance increases with advanced aging ${ }^{73}$, stroke $^{74}$ or paralysis ${ }^{75}$ and this likely shifts the plantar flexor muscles to shorter operating lengths and faster shortening velocities, conditions that increase metabolic rate ${ }^{76,77}$. Furthermore, in cases where the foot-ankle complex becomes stiffer (e.g., diabetic neuropathy ${ }^{78}$ ), intervening by adding stiffness to the foot instead of the ankle joint may improve plantar flexor capacity by yielding slower, more economical shortening velocities. Finally, a device working in parallel with a stiffer MT than that of the ankle (e.g., hip flexors or extensors) might reduce underlying muscle activation predominantly by altering force demand without influencing force capacity (i.e., F-L, F-V operating points) due to a reduced decoupling between the muscle and joint.

Regarding the design and development of future exoskeletons, our results reaffirm that net power transfer from an exoskeleton is not necessary to reduce net metabolic rate during locomotion, even for young adults whose plantar flexor neuromechanics are near optimally tuned for economical force production ${ }^{21,31}$. This is primarily because net mechanical work from a device is not necessary to reduce the muscle activation rate of the user, a key factor driving metabolic savings from exoskeleton assistance (Table 2, Fig. 5). Since muscle activation rate is the metric that best captured the complex trade-off between changes in force demand and force capacity derived from exoskeleton assistance, it may be a useful foundation to build an updated roadmap for exoskeleton design. Typically, engineers and scientists have focused on building exoskeletons to reduce lower-limb joint moments and powers in order to reduce metabolic rate and is reflected in exoskeleton performance measurements (e.g., performance index ${ }^{79,80}$; augmentation factor ${ }^{19,59}$ ) that primarily relate reductions in biological mechanical power and net metabolic power of the user. But our results indicate no relationship between changes in users' metabolic rate and changes in mechanical power of the soleus muscle due to exoskeleton assistance (Table 2). In addition, other lines of evidence suggest that changes in biological mechanical power at the center of mass, joint-, or muscle-level ${ }^{14,36,56}$ are unable to explain how exoskeletons alter users metabolic rate. Taken together, these results motivate the need to incorporate muscle-level analyses into the design process for wearable devices intended to influence the dynamic function of musculoskeletal tissues.

The muscle-level links that we established between device function and user performance may provide guidance for achieving a more complete symbiosis between human and machine. Exoskeletons that can directly and seamlessly target muscle dynamics may provide even greater locomotion performance benefits than current devices, perhaps beyond improving walking economy. One approach, inspired in part by recent animal work where in vivo muscle lengths were used for closed-loop control of muscle force ${ }^{81}$, is to develop exoskeleton controllers that can sample muscle states in real-time and then steer (direct) them by updating device parameters in real-time ${ }^{36}$. This remains a formidable challenge in humans where direct measurements of underlying muscle dynamics are so far, too invasive. However, there is potential to use advanced tools from image processing and machine-learning to extract real-time muscle length and velocity samples from ultrasound images ${ }^{82}$, and then use them in combination with EMG or a musculoskeletal model ${ }^{83,84}$ as input to an exoskeleton controller. Access to muscle dynamics in real-time would enable application of state-of-the-art human in the loop optimization techniques ${ }^{17,85,86}$ to individual or groups of target muscles. The possibility of 'muscle in the loop' exoskeleton control strategies opens the door to devices capable of steering neuromechanical structure and function over both short and long timescales during locomotion ${ }^{87}$. The potential impact of wearable devices ranges from improving a runner's metabolic economy during a marathon; to altering sensory feedback for optimal rehabilitation post-stroke; to increasing the stiffness of the Achilles tendon to counteract the effects of aging. By implementing wearable devices that are symbiotic and highly adaptable, we have the potential to have a transformational impact on augmenting healthy and restoring pathological movement.

\section{Conclusions}

We used B-mode ultrasound imaging to measure in vivo soleus contraction dynamics and demonstrated that ankle exoskeleton rotational stiffnesses altered the normally tuned catapult behavior of the ankle plantar flexors. As stiffness increased, fascicle length and velocity increased and likely affected the muscle force production capacity as reflected in changes to the muscle force per activation calculation. Despite the general reduction in fascicle 

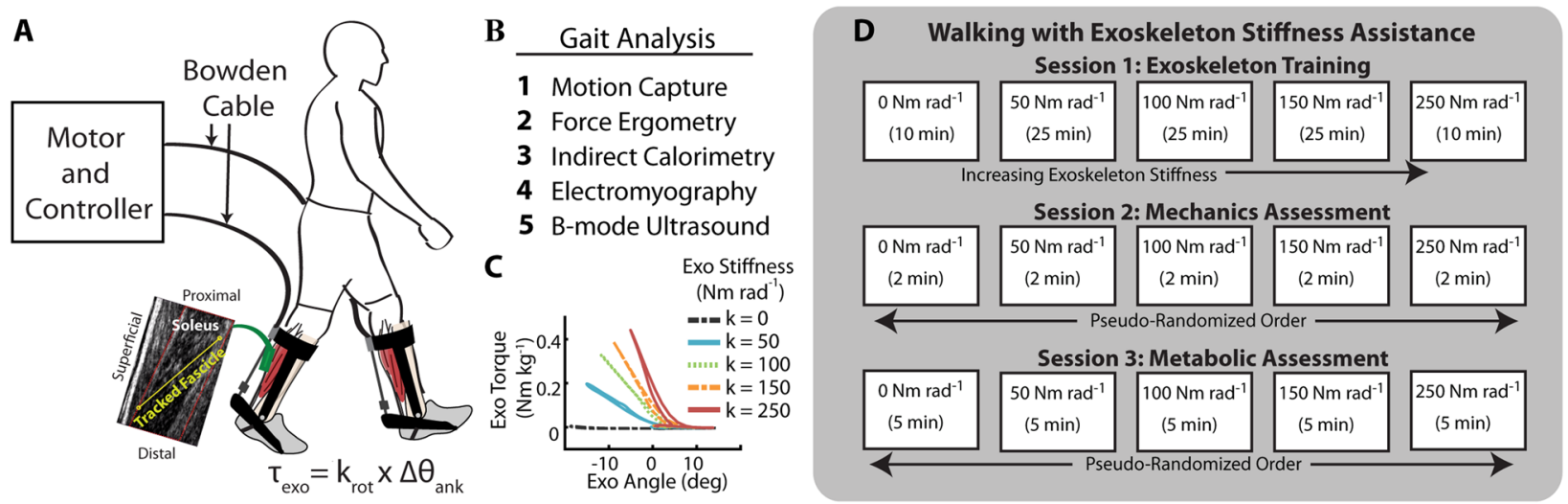

Figure 6. Elastic ankle exoskeleton test-bed and study protocol. (A) Representative setup of the exoskeleton testing platform for evaluating rotational stiffness plantar flexion assistance. The exoskeleton provided plantar flexion torque to the bilateral ankle exoskeletons through off-board motors. The controller emulated elastic rotational stiffness by imposing a torque angle relationship control law $\left(\tau_{\text {exo }}=\mathrm{k}_{\text {rot }} * \Delta \theta_{\text {ank }}\right)$. (B) In addition to traditional gait analysis tools, we used B-mode ultrasound to track soleus fascicle length changes while exoskeleton assistance was applied. (C) Stiffness could be changed in software and representative torqueangle profiles at each stiffness are shown. (D) Protocol for the three sessions. The imposed waiting period between each testing session was 2-7 days to allow for learning and retention ${ }^{88}$ and reduce fatigue. Participants were trained in the first session on all stiffnesses at $1.25 \mathrm{~m} \mathrm{~s}^{-1}$. During the second session, we recorded joint mechanics, electromyography (EMG), and ultrasound data for 5 exoskeleton conditions $\left(\mathrm{k}_{\mathrm{rot}}=0,50,100,150\right.$, $\left.250 \mathrm{Nm} \mathrm{rad}{ }^{-1}\right)$. In the third session, we recorded steady state metabolic cost for the same conditions.

force, the altered contractile dynamics help explain the 'bowl-shape' where an intermediate stiffness rather than high stiffness results in maximum metabolic benefit.

This work highlights the importance of linking exoskeleton-related changes in muscle dynamics to changes in users' metabolic rate and has implications for the design, application, and future development of exoskeletons beyond unpowered devices acting at the ankle.

\section{Methods}

Participants. Eleven healthy adults (4 female, 7 male, age: $27.7 \pm 3.3$ years, height: $1.75 \pm 0.07 \mathrm{~m}$, mass: $76.8 \pm 8.2 \mathrm{~kg}$ ) participated in the study. Participants had limited experience with the elastic ankle exoskeleton prior to the study. All participants signed an informed consent to participate in the study which was approved by the Institutional Review Board at The University of North Carolina at Chapel Hill. The methods were carried out in accordance with the IRB approved protocol.

Ankle exoskeleton testbed. The exoskeleton end effector was a lightweight carbon fiber ankle foot orthosis that applied plantar flexor torque to the ankle. The device consisted of bilateral ankle exoskeletons driven by benchtop motors (Fig. 6A). The control system imposed a torque angle relationship to emulate an elastic device providing rotational stiffness in parallel with the ankle. We calculated desired torque, $\tau_{\text {exo }}$ based off a predefined rotational stiffness and the real-time ankle angle measured using an electrogoniometer mounted to the exoskeleton shank and foot sections (Eq. 1)

$$
\tau_{\text {exo }}=k_{\text {exo }} \cdot\left(\theta_{0}-\theta_{\text {ankle }}\right)
$$

where $k_{\text {exo }}$ was exoskeleton rotational stiffness, $\theta_{0}$ was the onset angle, and $\theta_{\text {ankle }}$ was the real-time ankle angle (Fig. 6C).

Walking trials. Participants completed testing over three sessions where they walked at $1.25 \mathrm{~m} \mathrm{~s}^{-1}$ at five ankle exoskeleton rotational stiffness conditions $\left(\mathrm{k}_{\mathrm{exo}}=0,50,100,150,250 \mathrm{Nm} \mathrm{rad}^{-1}\right)$. The order of the three testing sessions was (1) exoskeleton training, (2) gait mechanics, (3) steady-state metabolic energy consumption (Fig. 6D). The imposed waiting period between each testing session was $2-7$ days to allow for learning and retention ${ }^{88}$

1. Training: Previous work has demonstrated the importance of training on the acceptance of mechanical assistance in exoskeletons ${ }^{80,89,90}$. Based off the training time from other studies ${ }^{26,80}$ and the time reported in other studies as the time required to metabolically adapt ${ }^{90}$, each participant walked in the exoskeleton at $1.25 \mathrm{~m} \mathrm{~s}^{-1}$ for a total of 95 minutes over 5 training trials. The participants walked at each of intermediate stiffness conditions $\left(\mathrm{k}_{\text {exo }}=50,100,150 \mathrm{Nm} \mathrm{rad}^{-1}\right)$ for 25 -minute trials and at the lowest and highest stiffness conditions $\left(\mathrm{k}_{\mathrm{exo}}=0,250 \mathrm{Nm} \mathrm{rad}^{-1}\right)$ for 10 minutes. We collected indirect calorimetry data for each of the trials to monitor changes in metabolic energy use over the course of the training session. 
2. Gait mechanics: Participants walked for 2 minutes at each of the 5 exoskeleton stiffness trials in a randomized order. We instrumented participants with surface electromyography on the left shank $(120 \mathrm{~Hz}$, Vicon, Oxford, UK), and motion capture markers on the lower limbs and pelvis. Due to space constraints, B-mode ultrasound was placed over the right soleus.

3. Steady state metabolic energy expenditure: We collected indirect calorimetry data for each walking trial. To allow participants' metabolic rate to reach steady state, each walking trial lasted 5 minutes. The order of the steady state metabolic conditions was re-randomized.

Metabolic energy consumption measurements. We calculated mass-specific net metabolic power (W $\mathrm{kg}^{-1}$ ) using a portable indirect calorimetry system (OxyCon Mobile, Vyaire Medical, Mettawa, IL) and applying standard indirect calorimetry equations ${ }^{91}$. To obtain net metabolic power for each condition, we subtracted the average metabolic power collected during the standing trials from metabolic power recorded during the walking conditions. To estimate steady-state, mass-specific, net rate of metabolic energy expenditure, we averaged the breath-by-breath data for the last minute of each five-minute trial and divided by body mass.

Joint kinematics and kinetics measurements. We measured lower-limb joint kinematics using a reflective marker motion capture system $(120 \mathrm{~Hz}$, Vicon, Oxford, UK) whereby the participant was instrumented with 44 reflective markers to capture the 6-DOF motion of the foot, shank, thigh, and pelvis. We calculated joint angles from the marker data and joint velocity was calculated as the first derivative of joint angle (Visual 3D, C-Motion Germantown, MD). A split-belt instrumented treadmill $(980 \mathrm{~Hz}, \mathrm{Bertec}$, Columbus, $\mathrm{OH})$ measured ground reaction forces (GRFs). We performed inverse dynamic analysis to calculate net joint moments $\left(\mathrm{Nm} \mathrm{kg}^{-1}\right)$ for the ankle, knee, and hip (Visual 3D, C-Motion Germantown, MD). We filtered marker positions at $6 \mathrm{~Hz}$ and analog data (e.g., GRFs, exoskeleton forces) were filtered at $25 \mathrm{~Hz}$. We calculated biological contribution to ankle moment by subtracting the directly measured exoskeleton torque from the net ankle moment. Joint angles and moments are reported for the sagittal plane. We calculated rigid foot, 6-DOF joint power using techniques similar to Zelik et al. ${ }^{92}$.

For each participant, we calculated an average stride for each of the 5 conditions by time normalizing each stride between heel-strike and heel-strike of the subsequent stride. We then averaged multiple strides (15.5 \pm 1.1$)$ together to obtain a single normalized stride for each condition. We calculated integrated and peak values prior to inter-stride averaging. Peak values for a given measurement and condition were the average of the peaks for each stride within that condition. Stride and stance average mass-specific joint moment and power was the integral of the moment/power for each stride/stance period and dividing by stride/stance time and participant mass. To obtain the average moment per unit time, we divided again by the stride/stance time over which the integral was taken to obtain the average moment rate $\left(\mathrm{Nm} \mathrm{kg}^{-1} \mathrm{~s}^{-1}\right)$. (Note: This rate represents an average moment per unit time and is not a measure of how rapidly the moment is generated).

Muscle activity measurements. We measured muscle activity of the ankle plantar flexors (medial and lateral gastrocnemius, soleus) and ankle dorsiflexor (tibialis anterior) using surface electromyography on the left leg (SX230, Biometrics Ltd, Newport, UK). To obtain an EMG envelope, we high-pass filtered at $20 \mathrm{~Hz}$ the raw EMG data, rectified, and low-pass filtered at $10 \mathrm{~Hz}$ (zero-phase $2^{\text {nd }}$ order Butterworth). Integrated EMG (iEMG) was the time-integral of the EMG envelope averaged across each stride for a condition. We then normalized amplitude of the EMG envelope and the iEMG for each muscle to the peak amplitude for the muscle across all conditions for each participant. Then, we divided the iEMG by the time period over which it was integrated to get the average EMG. Finally, to get average muscle activation per unit time, we again divided the average EMG by the time period over which it was averaged to obtain average muscle activation (EMG) rate $\left(\mathrm{s}^{-1}\right)$. Average muscle activation rates over distinct phases of the stride was the average muscle activation over that phase divided by the time accrued during that phase. Phases examined were: all of stance (0-60\%), early stance (0-40\%) and late stance $(40-60 \%)$ of the stride. (Note: This rate represents an average activation per unit time and is not a measure of how rapidly the muscle turns on and off).

Muscle-tendon dynamics measurements. We recorded B-mode ultrasound images of the soleus muscle using a linear probe ultrasound system (LV 7.5/60/96Z, Telemed, Lithuania). We positioned the probe over the right soleus below the contact point with the exoskeleton and secured with elastic adhesive wrap. We digitized ultrasound images using automated tracking software to determine time-varying soleus fascicle lengths and pennation angles during walking ${ }^{93-95}$. We manually selected a region of interest (soleus muscle belly) and the fascicle of interest, in the mid-region of the muscle belly, in an initial frame. The algorithm then tracks the fascicle in sequential frames by implementing an affine flow model. The UltraTrack ${ }^{95}$ program also incorporates a 'key-frame correction' algorithm that assists with removing temporal drift. For each step, we determined the corresponding index for the maximum dorsiflexion angle (from synced motion capture) and used it in the key-frame correction. However, key-frame correction assumes that errors accumulate linearly, which is not always appropriate for cyclical movements. When key-frame correction did not provide satisfactory results and tracking results were poor, manual corrections were made. Manual corrections were most commonly made during the swing phase, when fascicle lengthening was greatest. A square wave digital pulse from the ultrasound system initiated the capture synched the US data with the motion capture data. We incorporated the timing delay between systems in the analysis.

We calculated plantar flexor muscle-tendon (MT) force and length from biological ankle joint kinematics and kinetics ${ }^{96}$ using methods similar to previous studies ${ }^{69}$. We calculated total MT force $F_{M T}$, by dividing the net ankle joint moment $M_{a n k}$, by the MT moment arm about the ankle joint center $m a_{a n k}$, over the stride. The moment arm 
was derived from the relationship between the MTU length and the measured ankle angle similar to previous work $^{69}$. Then, we estimated the contribution from the soleus to total MT force as the ratio of the cross-sectional area (CSA) of the soleus muscle to the total plantar flexor muscle cross sectional area $(=0.54)^{72}$. Next, we calculated soleus muscle force $F_{M_{\text {totol }}}$, by dividing the soleus MT force contribution by the cosine of the measured soleus fascicle pennation angle $\theta_{p}$, over the stride (Eq. 2; equivalent to Eq. S3).

$$
F_{M_{\text {total }}}=\left[\frac{M_{\text {ank }}}{m a_{\text {ank }}}\right] \cdot C S A / \cos \theta_{p}
$$

$F_{M}$ was divided by participant mass to get a mass normalized soleus muscle force $\left(\mathrm{N} \mathrm{kg}^{-1}\right)$. Soleus muscle fascicle velocity was the first derivative of fascicle length. For each participant, we calculated time-domain measurements for each condition by time normalizing each stride between heel-strike and heel-strike of the subsequent stride. We averaged together a minimum of three normalized strides ( $6 \pm 0.6$ stride average) to obtain a single normalized stride for a given condition. Integrated and peak values were calculated prior to inter-stride averaging. We calculated soleus muscle fascicle length at the time of peak force with the intention of observing changes in fascicle length due to changes in MT stretch. For each condition, we then averaged the length measured at peak force for at least three strides. Researchers were not blinded to the conditions during processing, but conditions were processed in random order.

Finally, to evaluate the influence of force-length (F-L) and force-velocity (F-V) effects on the capacity of the soleus muscle to produce force we computed its force per activation $\left(\mathrm{N} \mathrm{kg}^{-1}\right)$ (see S1, Eq. S7 for details on this metric). To do this we divided the average muscle force rate by the average muscle activation rate over the same distinct phases of the stride described previously for force and activation measures (i.e., all of stance (0-60\%), early stance $(0-40 \%)$ and late stance (40-60\%) of the stride).

Statistics. Statistical analyses were performed on the exoskeleton conditions $\left(\mathrm{k}_{\mathrm{exo}}=0-250 \mathrm{Nm} \mathrm{rad}^{-1}\right)$ to isolate the role of exoskeleton rotational stiffness rather than the effect of the added mass of the exoskeleton and other structural impacts of the device. For ankle joint dynamics $(n=11)$, muscle-tendon dynamics $(n=10)$, muscle activity $(n=10)$, and net metabolic energy rate $(n=11)$, we report the means and standard errors calculated across participants. We note that dynamic ultrasound data was excluded for 1 of the 11 participants due to inability to track that participant's data. Muscle level analysis for this participant was excluded from our analyses. Metrics describing soleus muscle fascicle dynamics (i.e., force, activation, length, velocity) were the primary outcome measures examined in this study. To address our hypotheses, we performed a series of two-factor ANOVA (mixed-model, random effect: participant; main effect: $k_{\text {exo }}$ ) analyses to test for an effect of exoskeleton stiffness $\mathrm{k}_{\text {exo }}$, on soleus muscle force rate, activation rate, fascicle length, fascicle velocity, and force per activation (JMP Pro, SAS, Cary, NC). A Shapiro-Wilk W test confirmed normality of the data. For dependent variables showing a significant main effect $(p<\alpha=0.05)$ of exoskeleton stiffness, a Tukey's Honestly Significant Difference Test (THSD) ${ }^{97}$ was used to reveal pairwise differences between conditions. Finally, we performed a number of within-participant, linear, least-squares regression (LLSR) analyses to test for relationships $\left(p<\alpha=0.05 ; \mathrm{R}^{2}\right)$ between changes in soleus muscle neuromechanics (e.g., positive power = positive work rate, force, force rate, activation, activation rate, force/activation) and changes in whole body net metabolic rate due to increasing exoskeleton stiffness.

\section{Data availability}

Source data from this study in .mat and .txt format and an associated readme.txt for navigating it are available for download at: http://pwp.gatech.edu/hpl/archival-data-from-publications/.

Received: 23 September 2019; Accepted: 7 February 2020;

Published online: 27 February 2020

\section{References}

1. Farris, D. J. \& Sawicki, G. S. Human medial gastrocnemius force-velocity behavior shifts with locomotion speed and gait. Proc. Natl Acad. Sci. USA 109, 977-982, https://doi.org/10.1073/pnas.1107972109 (2012).

2. Kuo, A. D., Donelan, J. M. \& Ruina, A. Energetic consequences of walking like an inverted pendulum: step-to-step transitions. Exerc. Sport. Sci. Rev. 33, 88-97, https://doi.org/10.1097/00003677-200504000-00006 (2005).

3. Roberts, T. J. The integrated function of muscles and tendons during locomotion. Comp. Biochem. Physiol. A Mol. Integr. Physiol 133, 1087-1099, https://doi.org/10.1016/s1095-6433(02)00244-1 (2002).

4. Biewener, A. A. \& Roberts, T. J. Muscle and tendon contributions to force, work, and elastic energy savings: a comparative perspective. Exerc. Sport. Sci. Rev. 28, 99-107 (2000).

5. Roberts, T. J. \& Azizi, E. Flexible mechanisms: the diverse roles of biological springs in vertebrate movement. J. Exp. Biol. 214, 353-361, https://doi.org/10.1242/jeb.038588 (2011).

6. Fukunaga, T. et al. In vivo behaviour of human muscle tendon during walking. Proceedings. Biol. Sci. 268, 229-233, https://doi. org/10.1098/rspb.2000.1361 (2001).

7. Ishikawa, M., Komi, P. V., Grey, M. J., Lepola, V. \& Bruggemann, G. P. Muscle-tendon interaction and elastic energy usage in human walking. J. Appl. Physiol. 99, 603-608, https://doi.org/10.1152/japplphysiol.00189.2005 (2005).

8. Rubenson, J., Pires, N. J., Loi, H. O., Pinniger, G. J. \& Shannon, D. G. On the ascent: the soleus operating length is conserved to the ascending limb of the force-length curve across gait mechanics in humans. The Journal of experimental biology 215, 3539-3551, jeb.070466 (2012)

9. Hill, A. V. Length of muscle, and the heat and tension developed in an isometric contraction. J. Physiol. 60, 237-263, https://doi. org/10.1113/jphysiol.1925.sp002242 (1925).

10. Hill, A. V. The heat of shortening and the dynamic constants of muscle. Proc. R. Soc. London. Ser. B - Biol. Sci. 126, 136-195, https:// doi.org/10.1098/rspb.1938.0050 (1938). 
11. Gordon, A. M., Huxley, A. F. \& Julian, F. J. The variation in isometric tension with sarcomere length in vertebrate muscle fibres. J. Physiol. 184, 170-192, https://doi.org/10.1113/jphysiol.1966.sp007909 (1966).

12. Lai, A. et al. In vivo behavior of the human soleus muscle with increasing walking and running speeds. J. Appl. Physiol. 118, 1266-1275, https://doi.org/10.1152/japplphysiol.00128.2015 (2015).

13. Sawicki, G. S., Beck, O. N., Kang, I. \& Young, A. The exoskeleton expansion. Journal of NeuroEngineering and Rehabilitation ((In review)) (2019).

14. Galle, S., Malcolm, P., Collins, S. H. \& De Clercq, D. Reducing the metabolic cost of walking with an ankle exoskeleton: interaction between actuation timing and power. J. Neuroeng. Rehabil. 14, 35, https://doi.org/10.1186/s12984-017-0235-0 (2017).

15. Malcolm, P., Derave, W., Galle, S. \& De Clercq, D. A simple exoskeleton that assists plantarflexion can reduce the metabolic cost of human walking. PLoS one 8, e56137, https://doi.org/10.1371/journal.pone.0056137 (2013).

16. Quinlivan, B. et al. Assistance magnitude versus metabolic cost reductions for a tethered multiarticular soft exosuit. Sci. Robot. 2, eaah4416 (2017).

17. Zhang, J. et al. Human-in-the-loop optimization of exoskeleton assistance during walking. Sci. 356, 1280-1284, https://doi. org/10.1126/science.aal5054 (2017).

18. Malcolm, P., Galle, S., Derave, W. \& De Clercq, D. Bi-articular Knee-Ankle-Foot Exoskeleton Produces Higher Metabolic Cost Reduction than Weight-Matched Mono-articular Exoskeleton. Front. Neurosci. 12, 69, https://doi.org/10.3389/fnins.2018.00069 (2018).

19. Mooney, L. M., Rouse, E. J. \& Herr, H. M. Autonomous exoskeleton reduces metabolic cost of human walking during load carriage. J. Neuroeng. Rehabil. 11, 80, https://doi.org/10.1186/1743-0003-11-80 (2014).

20. Mooney, L. M., Rouse, E. J. \& Herr, H. M. Autonomous exoskeleton reduces metabolic cost of human walking. J. Neuroeng. Rehabil. 11, 151, https://doi.org/10.1186/1743-0003-11-151 (2014).

21. Seo, K., Lee, J. \& Park, Y. J. Autonomous hip exoskeleton saves metabolic cost of walking uphill. IEEE. Int. Conf. RehabilitatiRobotics: [Proc.] 2017, 246-251, https://doi.org/10.1109/ICORR.2017.8009254 (2017).

22. Kim, J. et al. Reducing the metabolic rate of walking and running with a versatile, portable exosuit. Sci. 365, 668-672, https://doi. org/10.1126/science.aav7536 (2019).

23. Awad, L. N. et al. A soft robotic exosuit improves walking in patients after stroke. Science translational medicine 9, https://doi. org/10.1126/scitranslmed.aai9084 (2017).

24. Lee, H. J. et al. A Wearable Hip Assist Robot Can Improve Gait Function and Cardiopulmonary Metabolic Efficiency in Elderly Adults. IEEE Trans. Neural Syst. Rehabil. Eng. 25, 1549-1557, https://doi.org/10.1109/TNSRE.2017.2664801 (2017).

25. Galle, S. et al. Exoskeleton plantarflexion assistance for elderly. Gait Posture 52, 183-188, https://doi.org/10.1016/j. gaitpost.2016.11.040 (2017)

26. Collins, S. H., Wiggin, M. B. \& Sawicki, G. S. Reducing the energy cost of human walking using an unpowered exoskeleton. Nat. https://doi.org/10.1038/nature14288 (2015).

27. Farris, D. J., Hicks, J. L., Delp, S. L. \& Sawicki, G. S. Musculoskeletal modelling deconstructs the paradoxical effects of elastic ankle exoskeletons on plantar-flexor mechanics and energetics during hopping. J. Exp. Biol. 217, 4018-4028, https://doi.org/10.1242/ jeb.107656 (2014).

28. Robertson, B. D., Farris, D. J. \& Sawicki, G. S. More is not always better: modeling the effects of elastic exoskeleton compliance on underlying ankle muscle-tendon dynamics. Bioinspiration Biomim. 9, 046018 (2014).

29. Jackson, R. W., Dembia, C. L., Delp, S. L. \& Collins, S. H. Muscle-tendon mechanics explain unexpected effects of exoskeleton assistance on metabolic rate during walking. J. Exp. Biol. 220, 2082-2095, https://doi.org/10.1242/jeb.150011 (2017).

30. Sawicki, G. S. \& Khan, N. S. A Simple Model to Estimate Plantarflexor Muscle-Tendon Mechanics and Energetics During Walking With Elastic Ankle Exoskeletons. IEEE Trans. Biomed. Eng. 63, 914-923, https://doi.org/10.1109/TBME.2015.2491224 (2016).

31. Dembia, C. L., Silder, A., Uchida, T. K., Hicks, J. L. \& Delp, S. L. Simulating ideal assistive devices to reduce the metabolic cost of walking with heavy loads. PLoS One 12, e0180320, https://doi.org/10.1371/journal.pone.0180320 (2017).

32. Uchida, T. K. et al. Simulating Ideal Assistive Devices to Reduce the Metabolic Cost of Running. PLoS One 11, e0163417, https://doi. org/10.1371/journal.pone.0163417 (2016).

33. Farris, D. J., Robertson, B. D. \& Sawicki, G. S. Elastic ankle exoskeletons reduce soleus muscle force but not work in human hopping. J. Appl. Physiol. 115, 579-585, https://doi.org/10.1152/japplphysiol.00253.2013 (2013).

34. Robertson, B. D., Vadakkeveedu, S. \& Sawicki, G. S. A benchtop biorobotic platform for in vitro observation of muscle-tendon dynamics with parallel mechanical assistance from an elastic exoskeleton. J. Biomech. 57, 8-17, https://doi.org/10.1016/j. jbiomech.2017.03.009 (2017).

35. Choi, H. et al. Impact of ankle foot orthosis stiffness on Achilles tendon and gastrocnemius function during unimpaired gait. $J$. Biomech. 64, 145-152, https://doi.org/10.1016/j.jbiomech.2017.09.015 (2017).

36. Beck, O. N., Punith, L. K., Nuckols, R. W. \& Sawicki, G. S. Exoskeletons Improve Locomotion Economy by Reducing Active Muscle Volume. Exerc. Sport. Sci. Rev. 47, 237-245, https://doi.org/10.1249/JES.0000000000000204 (2019).

37. McMahon, T. A. Muscles, reflexes, and locomotion. Princeton, Princeton (1984).

38. Zajac, F. E. Muscle and tendon: properties, models, scaling, and application to biomechanics and motor control. Crit. Rev. Biomed. Eng. 17, 359-411 (1989)

39. Fenn, W. \& Marsh, B. Muscular force at different speeds of shortening. J. Physiol. 85, 277 (1935).

40. Arnold, E. M., Ward, S. R., Lieber, R. L. \& Delp, S. L. A model of the lower limb for analysis of human movement. Ann. Biomed. Eng. 38, 269-279, https://doi.org/10.1007/s10439-009-9852-5 (2010).

41. Hilber, K., Sun, Y. B. \& Irving, M. Effects of sarcomere length and temperature on the rate of ATP utilisation by rabbit psoas muscle fibres. J. Physiol. 531, 771-780, https://doi.org/10.1111/j.1469-7793.2001.0771h.x (2001).

42. Gollapudi, S. K. \& Lin, D. C. Experimental determination of sarcomere force-length relationship in type-I human skeletal muscle fibers. J. Biomech. 42, 2011-2016, https://doi.org/10.1016/j.jbiomech.2009.06.013 (2009).

43. Alexander, R. M. Optimum muscle design for oscillatory movements. J. Theor. Biol. 184, 253-259 (1997).

44. Roberts, T. J., Chen, M. S. \& Taylor, C. R. Energetics of bipedal running. II. Limb design and running mechanics. J. Exp. Biol. 201, 2753-2762 (1998)

45. Roberts, T. J., Kram, R., Weyand, P. G. \& Taylor, C. R. Energetics of bipedal running. I. Metabolic cost of generating force. J. Exp. Biol. 201, 2745-2751 (1998).

46. Taylor, C. R. Relating mechanics and energetics during exercise. Adv. veterinary Sci. Comp. Med. 38A, 181-215 (1994).

47. Griffin, T. M., Roberts, T. J. \& Kram, R. Metabolic cost of generating muscular force in human walking: insights from load-carrying and speed experiments. J. Appl. Physiol. 95, 172-183, https://doi.org/10.1152/japplphysiol.00944.2002 (2003)

48. Biewener, A. A., Farley, C. T., Roberts, T. J. \& Temaner, M. Muscle mechanical advantage of human walking and running: implications for energy cost. J. Appl. Physiol. 97, 2266-2274, https://doi.org/10.1152/japplphysiol.00003.2004 (2004).

49. Kipp, S., Grabowski, A. M. \& Kram, R. What determines the metabolic cost of human running across a wide range of velocities? J Exp Biol 221, https://doi.org/10.1242/jeb.184218 (2018).

50. Kram, R. \& Taylor, C. R. Energetics of running: a new perspective. Nat. 346, 265-267, https://doi.org/10.1038/346265a0 (1990).

51. Nuckols, R. W. \& Sawicki, G. S. Impact of elastic ankle exoskeleton stiffness on neuromechanics and energetics of human walking across multiple speeds. J. Neuroeng. Rehabil ((In review)). Preprint available at https://doi.org/10.21203/rs.2.20510/v1 (2020). 
52. Umberger, B. R. \& Rubenson, J. Understanding muscle energetics in locomotion: new modeling and experimental approaches. Exerc. Sport. Sci. Rev. 39, 59-67, https://doi.org/10.1097/JES.0b013e31820d7bc5 (2011).

53. Neptune, R. R., Sasaki, K. \& Kautz, S. A. The effect of walking speed on muscle function and mechanical energetics. Gait Posture 28, 135-143, https://doi.org/10.1016/j.gaitpost.2007.11.004 (2008).

54. Farris, D. J. \& Sawicki, G. S. Linking the mechanics and energetics of hopping with elastic ankle exoskeletons. J. Appl. Physiol. 113, 1862-1872, https://doi.org/10.1152/japplphysiol.00802.2012 (2012).

55. Carrier, D. R., Anders, C. \& Schilling, N. The musculoskeletal system of humans is not tuned to maximize the economy of locomotion. Proc. Natl Acad. Sci. USA 108, 18631-18636, https://doi.org/10.1073/pnas.1105277108 (2011).

56. Jackson, R. W. \& Collins, S. H. An experimental comparison of the relative benefits of work and torque assistance in ankle exoskeletons. J. Appl. Physiol. 119, 541-557, https://doi.org/10.1152/japplphysiol.01133.2014 (2015).

57. Kao, P. C., Lewis, C. L. \& Ferris, D. P. Invariant ankle moment patterns when walking with and without a robotic ankle exoskeleton. J. Biomech. 43, 203-209, https://doi.org/10.1016/j.jbiomech.2009.09.030 (2010).

58. Koller, J. R., Jacobs, D. A., Ferris, D. P. \& Remy, C. D. Learning to walk with an adaptive gain proportional myoelectric controller for a robotic ankle exoskeleton. J. Neuroeng. Rehabil. 12, 97, https://doi.org/10.1186/s12984-015-0086-5 (2015).

59. Mooney, L. M. \& Herr, H. M. Biomechanical walking mechanisms underlying the metabolic reduction caused by an autonomous exoskeleton. J. Neuroeng. Rehabil. 13, 4, https://doi.org/10.1186/s12984-016-0111-3 (2016).

60. Morgan, D. L. New insights into the behavior of muscle during active lengthening. Biophysical J. 57, 209-221, https://doi. org/10.1016/S0006-3495(90)82524-8 (1990).

61. Morgan, D. L. \& Allen, D. G. Early events in stretch-induced muscle damage. J. Appl. Physiol. 87, 2007-2015, https://doi.org/10.1152/ jappl.1999.87.6.2007 (1999)

62. Allinger, T. L., Epstein, M. \& Herzog, W. Stability of muscle fibers on the descending limb of the force-length relation. A theoretical consideration. J. Biomech. 29, 627-633, https://doi.org/10.1016/0021-9290(95)00087-9 (1996).

63. Lieber, R. L. \& Friden, J. Muscle damage is not a function of muscle force but active muscle strain. J. Appl. Physiol. 74, 520-526 (1993).

64. Nichols, T. R. \& Houk, J. C. Improvement in linearity and regulation of stiffness that results from actions of stretch reflex. J. Neurophysiol. 39, 119-142, https://doi.org/10.1152/jn.1976.39.1.119 (1976).

65. Nichols, T. R. \& Houk, J. C. Reflex compensation for variations in the mechanical properties of a muscle. Sci. 181, 182-184, https:// doi.org/10.1126/science.181.4095.182 (1973).

66. Houk, J. C. Regulation of stiffness by skeletomotor reflexes. Annu. Rev. Physiol. 41, 99-114, https://doi.org/10.1146/annurev. ph.41.030179.000531 (1979).

67. Enoka, R. M. Neuromechanics of human movement. (Human kinetics, 2008).

68. Sawicki G.S., Nardelli P., Cope T.C., "A novel work loop approach for decoding sensory information in afferent nerves during cyclic muscle contractions". 46th Annual Meeting of the Society for Neuroscience (SfN), (2016).

69. Takahashi, K. Z., Gross, M. T., van Werkhoven, H., Piazza, S. J. \& Sawicki, G. S. Adding Stiffness to the Foot Modulates Soleus ForceVelocity Behaviour during Human Walking. Sci. Rep. 6, 29870, https://doi.org/10.1038/srep29870 (2016).

70. Maganaris, C. N. Imaging-based estimates of moment arm length in intact human muscle-tendons. Eur. J. Appl. Physiol. 91, 130-139, https://doi.org/10.1007/s00421-003-1033-x (2004).

71. Maganaris, C. N., Baltzopoulos, V. \& Sargeant, A. J. Changes in Achilles tendon moment arm from rest to maximum isometric plantarflexion: in vivo observations in man. J. Physiol. 510(Pt 3), 977-985, https://doi.org/10.1111/j.1469-7793.1998.977bj.x (1998).

72. Fukunaga, T. et al. Physiological cross-sectional area of human leg muscles based on magnetic resonance imaging. J. Orthop. Res. 10, 928-934, https://doi.org/10.1002/jor.1100100623 (1992).

73. Stenroth, L., Peltonen, J., Cronin, N. J., Sipila, S. \& Finni, T. Age-related differences in Achilles tendon properties and triceps surae muscle architecture in vivo. J. Appl. Physiol. 113, 1537-1544, https://doi.org/10.1152/japplphysiol.00782.2012 (2012).

74. Zhao, H., Ren, Y., Wu, Y. N., Liu, S. Q. \& Zhang, L. Q. Ultrasonic evaluations of Achilles tendon mechanical properties poststroke. J. Appl. Physiol. 106, 843-849, https://doi.org/10.1152/japplphysiol.91212.2008 (2009).

75. Maganaris, C. N. et al. Adaptive response of human tendon to paralysis. Muscle nerve 33, 85-92, https://doi.org/10.1002/mus.20441 (2006).

76. Stenroth, L., Sipila, S., Finni, T. \& Cronin, N. J. Slower Walking Speed in Older Men Improves Triceps Surae Force Generation Ability. Med. Sci. sports Exerc. 49, 158-166, https://doi.org/10.1249/MSS.0000000000001065 (2017).

77. Orselli, M. I. V., Franz, J. R. \& Thelen, D. G. The effects of Achilles tendon compliance on triceps surae mechanics and energetics in walking. J. Biomech. 60, 227-231, https://doi.org/10.1016/j.jbiomech.2017.06.022 (2017).

78. Petrovic, M. et al. Altered Achilles tendon function during walking in people with diabetic neuropathy: implications for metabolic energy saving. J. Appl. Physiol. 124, 1333-1340, https://doi.org/10.1152/japplphysiol.00290.2017 (2018).

79. Sawicki, G. S. \& Ferris, D. P. Mechanics and energetics of incline walking with robotic ankle exoskeletons. J. Exp. Biol. 212, 32-41, https://doi.org/10.1242/jeb.017277 (2009).

80. Sawicki, G. S. \& Ferris, D. P. Mechanics and energetics of level walking with powered ankle exoskeletons. J. Exp. Biol. 211, 1402-1413, https://doi.org/10.1242/jeb.009241 (2008).

81. Srinivasan, S. S., Maimon, B. E., Diaz, M., Song, H. \& Herr, H. M. Closed-loop functional optogenetic stimulation. Nat. Commun. 9 , 5303, https://doi.org/10.1038/s41467-018-07721-w (2018).

82. Cunningham, R. J., Harding, P. J. \& Loram, I. D. The application of deep convolutional neural networks to ultrasound for modelling of dynamic states within human skeletal muscle. CoRR abs/1706.09450 (2017).

83. Durandau, G., Farina, D. \& Sartori, M. Robust Real-Time Musculoskeletal Modeling Driven by Electromyograms. IEEE Trans. Biomed. Eng. 65, 556-564, https://doi.org/10.1109/TBME.2017.2704085 (2018).

84. Sartori, M., Yavuz, U. S. \& Farina, D. In Vivo Neuromechanics: Decoding Causal Motor Neuron Behavior with Resulting Musculoskeletal Function. Sci. Rep. 7, 13465, https://doi.org/10.1038/s41598-017-13766-6 (2017).

85. Felt, W., Selinger, J. C., Donelan, J. M. \& Remy, C. D. "Body-In-The-Loop”: Optimizing Device Parameters Using Measures of Instantaneous Energetic Cost. PLoS one 10, e0135342, https://doi.org/10.1371/journal.pone.0135342 (2015).

86. Kim, M. et al. Human-in-the-loop Bayesian optimization of wearable device parameters. PLoS One 12, e0184054, https://doi. org/10.1371/journal.pone.0184054 (2017).

87. Cox, S. M., Rubenson, J. \& Sawicki, G. S. "A soft-exosuit enables multi-scale analysis of wearable robotics in a bipedal animal model" IEEE/RSJ International Conference on Intelligent Robots and Systems (IROS). 4685-4691. (2018)

88. Schmidt, R. A. \& Lee, T. Motor control and learning. (Human kinetics, 1988).

89. Gordon, K. E. \& Ferris, D. P. Learning to walk with a robotic ankle exoskeleton. J. Biomech. 40, 2636-2644, https://doi.org/10.1016/j. jbiomech.2006.12.006 (2007).

90. Galle, S., Malcolm, P., Derave, W. \& De Clercq, D. Adaptation to walking with an exoskeleton that assists ankle extension. Gait posture 38, 495-499, https://doi.org/10.1016/j.gaitpost.2013.01.029 (2013).

91. Brockway, J. M. Derivation of formulae used to calculate energy expenditure in man. Hum. Nutr.Clinical nutrition 41, 463-471 (1987).

92. Zelik, K. E., Takahashi, K. Z. \& Sawicki, G. S. Six degree-of-freedom analysis of hip, knee, ankle and foot provides updated understanding of biomechanical work during human walking. J. Exp. Biol. 218, 876-886, https://doi.org/10.1242/jeb.115451 (2015). 
93. Cronin, N. J., Carty, C. P., Barrett, R. S. \& Lichtwark, G. Automatic tracking of medial gastrocnemius fascicle length during human locomotion. J. Appl. Physiol. 111, 1491-1496, https://doi.org/10.1152/japplphysiol.00530.2011 (2011).

94. Gillett, J. G., Barrett, R. S. \& Lichtwark, G. A. Reliability and accuracy of an automated tracking algorithm to measure controlled passive and active muscle fascicle length changes from ultrasound. Comput. Methods Biomech. Biomed. Engin 16, 678-687, https:// doi.org/10.1080/10255842.2011.633516 (2013).

95. Farris, D. J. \& Lichtwark, G. A. UltraTrack: Software for semi-automated tracking of muscle fascicles in sequences of B-mode ultrasound images. Comput. Methods Prog. Biomed. 128, 111-118, https://doi.org/10.1016/j.cmpb.2016.02.016 (2016).

96. Hawkins, D. \& Hull, M. L. A method for determining lower extremity muscle-tendon lengths during flexion/extension movements. J. Biomech. 23, 487-494, https://doi.org/10.1016/0021-9290(90)90304-1 (1990).

97. Abdi, H. \& Williams, L. J. Tukey's honestly significant difference (HSD) test. Encyclopedia of Research Design. Thousand Oaks, CA: Sage, 1-5 (2010).

\section{Acknowledgements}

We thank S. Steele-Pardue and T. Giest for assistance in assembling the exoskeleton device, T. Giest, J. McCall, and S. Philius for help with data collection and F. Shaw for help with data analysis. This research was supported by grants to G.S.S. from the National Robotics Initiative via the National Institute of Nursing Research of the National Institutes of Health (R01NR014756) and the U.S. Army Natick Soldier Research, Development and Engineering Center (W911QY18C0140). The content is solely the responsibility of the authors and does not necessarily represent the official views of the funding agencies listed.

\section{Author contributions}

R.W.N. and G.S.S. contributed equally to study design and direction; R.W.N. designed and fabricated the exoskeleton device; R.W.N conducted the human locomotion experiments; R.W.N., T.J.D., O.N.B. and G.S.S. analyzed the data; R.W.N., T.J.D., O.N.B. and G.S.S. drafted the manuscript; R.W.N., T.J.D., O.N.B. and G.S.S. edited the manuscript. All authors approved the final manuscript.

\section{Competing interests}

The authors declare no competing interests.

\section{Additional information}

Supplementary information is available for this paper at https://doi.org/10.1038/s41598-020-60360-4.

Correspondence and requests for materials should be addressed to R.W.N. or G.S.S.

Reprints and permissions information is available at www.nature.com/reprints.

Publisher's note Springer Nature remains neutral with regard to jurisdictional claims in published maps and institutional affiliations.

(c) (i) Open Access This article is licensed under a Creative Commons Attribution 4.0 International License, which permits use, sharing, adaptation, distribution and reproduction in any medium or format, as long as you give appropriate credit to the original author(s) and the source, provide a link to the Creative Commons license, and indicate if changes were made. The images or other third party material in this article are included in the article's Creative Commons license, unless indicated otherwise in a credit line to the material. If material is not included in the article's Creative Commons license and your intended use is not permitted by statutory regulation or exceeds the permitted use, you will need to obtain permission directly from the copyright holder. To view a copy of this license, visit http://creativecommons.org/licenses/by/4.0/.

(c) The Author(s) 2020 